\title{
RESEARCH
}

Open Access

\section{CaGdt1 plays a compensatory role for the calcium pump CaPmr1 in the regulation of calcium signaling and cell wall integrity signaling in Candida albicans}

Linghuo Jiang ${ }^{1 *+}$ D, Junjun Wang ${ }^{2+}$, Faiza Asghar ${ }^{1}$, Nathan Snyder ${ }^{3}$ and Kyle W. Cunningham ${ }^{3}$

\begin{abstract}
Background: Saccharomyces cerevisiae ScGdt1 and mammalian TMEM165 are two members of the UPF0016 membrane protein family that is likely to form a new group of $\mathrm{Ca}^{2+} / \mathrm{H}^{+}$antiporter and/or a $\mathrm{Mn}^{2+}$ transporter in the Golgi apparatus. We have previously shown that Candida albicans CaGDT1 is a functional ortholog of ScGDT1 in the response of S. cerevisiae to calcium stress. However, how CaGdt1 together with the Golgi calcium pump CaPmr1 regulate calcium homeostasis and cell wall integrity in this fungal pathogen remains unknown.
\end{abstract}

Methods: Chemical sensitivity was tested by dilution assay. Cell survival was examined by measuring colony-forming units and staining with Annexin V-FITC and propidium iodide. Calcium signaling was examined by expression of downstream target gene CaUTR2, while cell wall integrity signaling was revealed by detection of phosphorylated Mkc1 and Cek1. Subcellular localization of CaGdt1 was examined through direct and indirect immunofluorescent approaches. Transcriptomic analysis was carried out with RNA sequencing.

Results: This study shows that Candida albicans CaGDT1 is also a functional ortholog of ScGDT1 in the response of $S$. cerevisiae to cell wall stress. CaGdt1 is localized in the Golgi apparatus but at distinct sites from CaPmr1 in C. albicans. Loss of CaGDT1 increases the sensitivity of cell lacking CaPMR1 to cell wall and ER stresses. Deletion of CaGDT1 and/or CaPMR1 increases calcium uptake and activates the calcium/calcineurin signaling. Transcriptomic profiling reveals that core functions shared by CaGdt1 and CaPmr1 are involved in the regulation of cellular transport of metal ions and amino acids. However, CaGdt1 has distinct functions from CaPmr1. Chitin synthase gene CHS2 is up regulated in all three mutants, while CHS3 is only up regulated in the pmr1/pmr1 and the gdt1/gdt1 pmr1/pmr1 mutants. Five genes (DIE2, STT3, OST3, PMT1 and PMT4) of glycosylation pathway and one gene (SWI4) of the cell wall integrity (CWI) pathway are upregulated due to deletion of CaGDT1 and/or CaPMR1. Consistently, deletion of either CaPMR1 or CaGDT1 activates the CaCek1-mediated CWI signaling in a cell wall stress-independent fashion. Calcineurin function is required for the integrity of the cell wall and vacuolar compartments of cells lacking both GDT1 and CaPMR1.

Conclusions: CaPmr1 is the major player in the regulation of calcium homeostasis and cell wall stress, while CaGdt1 plays a compensatory role for CaPmr1 in the Golgi compartment in C. albicans.

Keywords: Candida albicans, Gdt1, Pmr1, Calcium homeostasis, Calcium signaling, Cell wall integrity signaling, Transcription profiling, Chs2, Chs3

\footnotetext{
* Correspondence: linghuojiang@sdut.edu.cn

${ }^{+}$Linghuo Jiang and Junjun Wang contributed equally to this work.

'Laboratory for Yeast Molecular and Cell Biology, School of Agricultural

Engineering and Food Science, Shandong University of Technology, Zibo,

Shandong, China

Full list of author information is available at the end of the article
}

(c) The Author(s). 2018 Open Access This article is distributed under the terms of the Creative Commons Attribution 4.0 International License (http://creativecommons.org/licenses/by/4.0/), which permits unrestricted use, distribution, and reproduction in any medium, provided you give appropriate credit to the original author(s) and the source, provide a link to the Creative Commons license, and indicate if changes were made. The Creative Commons Public Domain Dedication waiver (http://creativecommons.org/publicdomain/zero/1.0/) applies to the data made available in this article, unless otherwise stated. 


\section{Plain English summary}

Congenital disorders of glycosylation (CDG) are inherited diseases with most of their genetic defects affecting the glycosylation process. The human ortholog for yeast ScGdt1, TMEM165, is one of these CDG-associated Golgi proteins and might function as a $\mathrm{Ca}^{2+} / \mathrm{H}^{+}$antiporter and/or a $\mathrm{Mn}^{2+}$ transporter in the Golgi. This study provides evidence that the functional ortholog of ScGdt1, Candida albicans CaGdt1 plays a compensatory role for CaPmr1, the $\mathrm{Ca}^{2+} / \mathrm{Mn}^{2+}$ ATPase that is required for $\mathrm{Ca}^{2+}$ and $\mathrm{Mn}^{2+}$ transport into the Golgi and involved in $\mathrm{Ca}^{2+}$ dependent protein sorting processing. CaGdt1 and CaPmr1 work together at distinct sites of the Golgi apparatus to regulate the response of this human fungal pathogen to cell wall and ER stresses. Calcineurin function is required for the survival of $C$. albicans cells lacking both CaGdt1 and CaPmr1. These findings would contribute to our understanding of molecular mechanisms regulating TMEM165-associated CDG.

\section{Background}

Calcium ions regulate growth and programmed cell death as well as muscle contraction in the heart and taste in the mouth [1]. Calcium/calcineurin signaling pathway is highly conserved in eukaryotic cells. Functional counterparts of yeast calcium channels, pumps and exchangers exist and function in similar fashions in mammalian cells [2]. In Saccharomyces cerevisiae, calcium homeostasis is regulated through calcium transporters and sequestrates in the plasma and organelle membranes [2-4]. The plasma membrane calcium channel allows $\mathrm{Ca}^{2+}$ influx in response to endoplasmic reticulum (ER) stress and pheromones, while the vacuolar $\mathrm{Yvc1}$ releases $\mathrm{Ca}^{2+}$ into the cytosol in response to hypotonic shock $[4,5]$. Excess calcium ions are transported into the vacuole for storage through the vacuolar calcium pump Pmc1 and the $\mathrm{Ca}^{2+} / \mathrm{H}^{+}$exchanger Vcx1; or into the ER/Golgi secretory pathway via the calcium pump Pmr1 and the $\mathrm{Ca}^{2+} / \mathrm{H}^{+}$exchanger Gdt1 $[3,4,6]$. Expression of PMR1 is positively controlled by the calcium/calcineurin signaling pathway and negatively controlled by the Rim101/Nrg1 pathway in S. cerevisiae [7]. Functional counterparts of $\mathrm{Ca}^{2+}$ transporters and channels have been characterized in Candida albicans [8-11]. Rch1 is a novel negative regulator of calcium uptake in the plasma membrane of $S$. cerevisiae and $C$. albicans [12-15].

C. albicans is the most common human fungal pathogen in immunocompromised patients $[16,17]$. In $C$. albicans, there are four MAP kinases, Mkc1, Cek1, Cek2 and Hog1, with the former two mediating the cell wall integrity (CWI) pathway [18-21].
The cell wall of $C$. albicans is important in the interaction with its host during infection $[16,22]$. Deletion of CaPMR1 causes C. albicans cells to be hypersensitive to cell wall stress and to constitutively activate the Mkc1-mediated CWI signaling, which leads to a defect in glycosylation of cell wall proteins and thereby a weakened cell wall and reduced virulence [10]. C. albicans cells lacking $M K C 1$ or CEK1 also show a reduced virulence in the mouse model of systemic infection [23, 24]. Therefore, properly regulated CWI signaling is required for the virulence of C. albicans.

S. cerevisiae ScGdt1 and its human transmembrane protein 165 (TMEM165) belong to a well-conserved family of membrane proteins named UPF0016 (Uncharacterized Protein Family0016; Pfam PF01169), which exist in 919 bacterial species and 409 eukaryotic species [25]. Mutations of TMEM165 are linked to a subtype of inborn metabolic diseases affecting the glycosylation pathway, and TMEM165 is a functional homolog of the Golgi-localized ScGdt1 [7]. ScGdt1 may act as a $\mathrm{Ca}^{2+} / \mathrm{H}^{+}$antiporter and plays a major role in the calcium response induced by osmotic shock in the absence of ScPmr1 $[26,27]$. Here, we have characterized CaGdt1, the $C$. albicans homolog of $S$. cerevisiae ScGdt1, in the response to calcium and cell wall stress. CaGdt1 and CaPmr1 localize to distinct sites in the Golgi apartment. Transcriptomic profiling reveals overlapping and distinctive functions between CaGdt1 and CaPmr1. In addition, we demonstrate that CaGdt1 is involved in the Cek1-mediated, but not the Mkc1-mediated, cell signaling.

\section{Methods}

Strains and reagents

C. albicans and S. cerevisiae strains, plasmids and primers are listed in Tables 1 and 2, and Additional file 1: Table S1, respectively. All strains were routinely grown at $30{ }^{\circ} \mathrm{C}$ in YPD medium or SD medium $(0.67 \%$ yeast nitrogen base without amino acids, $2 \%$ glucose, and auxotrophic amino acids as needed). Chemical reagents were obtained from Sigma.

\section{Construction of $C$. albicans mutants}

We constructed the double-gene deletion mutant by replacing two CaGDT1 alleles in the pmr1/pmr1 mutant in the CAI4 background [10], with the SAT1 flipper cassette [28] and the hisG-URA3-hisG cassette [29], respectively, as described previously [30]. Genotypes of the resultant mutants were confirmed by PCR (data not shown). 
Table 1 Strains used in this study

\begin{tabular}{|c|c|c|}
\hline Strain & Genotype & Source \\
\hline \multicolumn{3}{|l|}{ S. cerevisiae } \\
\hline BY4741 & MATa his $3 \Delta 1$ leu $2 \Delta 0$ met15 $\Delta 0$ ura3 $\Delta 0$ & Invitrogen Inc. \\
\hline WJSC11 & BY4741 gdt1::kanMX4 & Invitrogen Inc. \\
\hline WJSC12 & BY4741 pmr1::kanMX4 & Invitrogen Inc. \\
\hline WJSC13 & BY4741 gdt1::natR pmr1::kanMX4 & Invitrogen Inc. \\
\hline \multicolumn{3}{|l|}{ C. albicans } \\
\hline RM1000 & 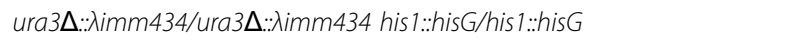 & [13] \\
\hline WJCA110 & RM1000 PMR1/PMR1::HA-HIS1 & This study \\
\hline WJCA111 & RM1000 PMR1/PMR1:: HA-HIS1 GDT1/GDT1:: GFP-URA3 & This study \\
\hline CAI4 & 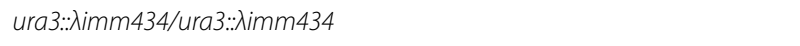 & [10] \\
\hline NGY98 & CAl4 pmr1::hisG/pmr1::hisG & [10] \\
\hline WJCAG22 & CAl4 gdt 1::hisG/gdt7::FRT & [30] \\
\hline WJCAG25 & CAl4 pmr1::hisG/pmr1::hisG gdt1::hisG/gdt1::FRT & This study \\
\hline WJCAG26 & CAI4 RPS1/rps1::Clp10 & This study \\
\hline WJCAG27 & CAl4 pmr1::hisG/pmr1::hisG RPS1/rps7::Clp10 & This study \\
\hline WJCAG28 & CAl4 gdt1::hisG/gdt1:: FRT RPS1/rps1::Clp10 & This study \\
\hline WJCAG29 & CAl4 pmr1::hisG/pmr1::hisG gdt1::hisG/gdt1:: FRT RPS1/rps 1::Clp10 & This study \\
\hline WJCA100 & CAl4 pmr1::hisG/pmr1::hisG gdt1::FRT/GDT1 & This study \\
\hline WJCA102 & CAI4 pmr1::hisG/pmr1::hisG gdt1::FRT/GDT1:: GFP-URA3 & This study \\
\hline WJCA201 & CAI4 MKC1/MKC1:: HA-URA3 & This study \\
\hline WJCA202 & CAl4 gdt1::hisG/gdt1::: FRT MKC1/MKC1::HA-URA3 & This study \\
\hline WJCA203 & CAl4 pmr1::hisG/pmr1::hisG MKC1/MKC1::HA-URA3 & This study \\
\hline WJCA204 & CAI4 pmr1::hisG/pmr1::hisG gdt1::hisG/gdt1:: FRT MKC1/MKC1::HA-URA3 & This study \\
\hline WJCA205 & CAI4 CEK1/CEK1::HA-URA3 & This study \\
\hline WJCA206 & CAl4 gdt1::hisG/gdt1:: FRT CEK1/CEK1::HA-URA3 & This study \\
\hline WJCA207 & CAI4 pmr1::hisG/pmr1::hisG CEK1/CEK1::HA-URA3 & This study \\
\hline WJCA208 & CAl4 pmr1::hisG/pmr1::hisG gdt1::hisG/gdt1:: FRT CEK1/CEK1::HA-URA3 & This study \\
\hline WJCA209 & CAI4 (UTR2p::LacZ reporter) & This study \\
\hline WJCA210 & CAl4 gdt1::hisG/gdt1:: FRT (UTR2p::LacZ reporter) & This study \\
\hline WJCA211 & CAl4 pmr1::hisG/pmr1::hisG (UTR2p::LacZ reporter) & This study \\
\hline WJCA212 & CAI4 pmr1::hisG/pmr1::hisG gdt1::hisG/gdt1:: FRT (UTR2p::Lac Z reporter) & This study \\
\hline
\end{tabular}

\section{DNA manipulation}

The 2150-bp CaGDT1 gene containing its promoter, ORF and 3 ' terminator was amplified from genomic DNA with primers GDT1 (BamHl) -UP and GDT1 (BamHl) DOWN, and cloned into the C. albicans expression vector pCR4 [13], which yielded pCR4-CaGDT1. Similarly, we amplified the CaGDT1 gene using the primers GDT1 (Kpnl) -UP and GDT1 (Sphl) -DOWN, and cloned it into the Kpnl and Sphl sites of S. cerevisiae vector pHAC181 [31], which yielded pHAC181-CaGDT1.

\section{Growth test}

Strains were cultured overnight in liquid YPD or SD-URA medium at $30{ }^{\circ} \mathrm{C}$. Overnight cultures were serially diluted by 10 -fold, and spotted onto appropriate plates. Phenotypes were recorded after plates were incubated for $2-3$ days at $30{ }^{\circ} \mathrm{C}$.

\section{${ }^{45} \mathrm{Ca}^{2+}$ uptake assays}

Cellular accumulation of $\mathrm{Ca}^{2+}$ was measured basically as described [32]. Cells were inoculated in YPD medium containing $5 \mu \mathrm{Ci} \mathrm{ml}^{-1}{ }^{45} \mathrm{CaCl}_{2}$ with a specific activity of $9.6 \times 10^{6} \mathrm{cpm} \mathrm{ml}^{-1}$ (PerkinElmer), and grown to $\log$ phase at $30{ }^{\circ} \mathrm{C}$ in 96 -well filtration plates. Cultures were harvested by filtration, washed four times with ice-cold buffer (5 mM Na-HEPES, pH 6.5, $10 \mathrm{mM} \mathrm{CaCl}_{2}$, $150 \mathrm{mM} \mathrm{NaCl}$ ), and dried at room temperature. The 
Table 2 Plasmids used in this study

\begin{tabular}{llll}
\hline Name & Description & Source \\
\hline pCR4 & C. albicans expression vector with CaURA3 marker & [13] \\
p5921 & C. albicans URA3 blaster cassette & [29] & This study \\
pCR4-CaGDT1 & Full-length CaGDT1 gene in pCR4 & [31] \\
pHAC181 & S. cerevisiae $2 \mu$ expression vector with LEU2 marker & This study \\
pHAC181-CaGDT1 & Full-length CaGDT1 gene in pHAC181 & [34] \\
pGFP-URA3 & GFP integration vector with URA3 marker & [34] \\
pFA-HA-URA3 & HA-epitope integration vector with CaURA3 marker & [34] \\
pFA-HA-HIS1 & HA-epitope integration vector with CdHIS1 marker & [28] \\
pSFS2 & the SAT1 flipper cassette & This study \\
pKC1 & Two flanking regions of CaGDT1 at either side of the hisG-URA3-hisG cassette in p5921 & [13] \\
pGP8 & Plasmid containing the 1-kb promoter of UTR2 fused to the lacZ reporter &
\end{tabular}

filters were counted using a TopCount NXT (Packard) liquid scintillation counter.

\section{Assays of $\beta$-galactosidase activity}

The CaUTR2p-lacZ reporter in the pGP8 plasmid [13] was integrated into the CaUTR2 locus in the wild type CAI4, the $g d t 1 / g d t 1$ mutant, the $p m r 1 / p m r 1$ mutant and the $g d t 1 / g d t 1 p m r 1 / p m r 1$ mutant. Three independent transformants of each strain were assayed for $\beta$-galactosidase activity as described previously [13].

\section{Analysis of cell survival and cell integrity}

Test strains were grown to log phase before the culture was divided into two parts, which were treated with $25 \mu \mathrm{g}$ $\mathrm{ml}^{-1} \mathrm{CsA}$ and ethanol (as control), respectively. Two parts were further incubated with shaking for $1 \mathrm{~h}, 2 \mathrm{~h}, 4 \mathrm{~h}$ and $8 \mathrm{~h}$, respectively, before samples were taken for measuring colony-forming units (clonogenic survival) as well as co-staining with $20 \mu \mathrm{g} \mathrm{ml}^{-1}$ Annexin V-FITC and $50 \mu \mathrm{g} \mathrm{ml}^{-1}$ propidium iodide (CLONETECH Laboratories, USA). Vacuoles in these cells were labelled in vivo with N-(3-triethylammoniumpropyl)-4-(6 [4-(diethylamino) phenyl) hexatrienyl] pyridinium dibromide (FM464; Molecular Probes, USA) as described [33].

\section{Protein extract and western blot analysis}

Cells were grown to mid-exponential phase, and treated with $50 \mu \mathrm{g} \mathrm{ml}^{-1}$ Calcofluor white for $2 \mathrm{~h}$ before they were collected for protein extraction and Western blot analysis as described [7]. The anti-phospho-p44/42 MAPK ( $\mathrm{Thr}^{202} / \mathrm{Tyr}^{204}$ ) antibody (Cell signaling, USA) was used to simultaneously detect phosphorylated forms of both CaMkc1 and CaCek1 [23, 24]. Anti-HA antibody (Abmart, Shanghai) was used to detect CaMkc1-HA and CaCek1-HA proteins [7].

\section{Chromosomal integration of green fluorescent protein} (GFP) and HA epitope

GFP tagging cassette was PCR-amplified with CaGDT1-GFP-UP and CaGDT1-GFP-DOWN from the pGFP-URA plasmid [34], using primers CaGDT1-GFP-UP and CaGDT1-GFP-down, and integrated into the heterozygous mutant (WJCA102). Genotype of the CaGDT1-GFP tagged strain with correct integration was confirmed by PCR (Additional file 1: Figure S2B). To examine the co-localization between CaGdt1 and CaPmr1, we first chromosomally tagged HA epitope to the C-terminus of CaPMR1 in the wild-type RM1000 strain, yielding RM1000 PMR1/PMR1::HA-HIS1 strain (WJCA110). The HA-HIS1 cassette was PCR-amplified with primers PMR1-HA -HIS-UP and PMR1-HA-HIS-DOWN from the pFA-HA -HIS1 plasmid [34, 35]. We subsequently tagged the GFP to the C-terminus of CaGDT1 in the WJCA110 strain, which generated the RM1000 PMR1/PMR1::HA-HIS1 GDT1/GDT1:: GFP-URA3 strain (WJCA111). Genotypes of WJCA110 and WJCA111 strains were confirmed by PCR (Additional file 1: Figure S2B).

Two HA-URA3 cassettes were PCR-amplified with primer pairs, MKC1-HA-UP/ MKC1-HA-DOWN and CEK1-HA-UP and CEK1-HA-DOWN, respectively, from the pFA-HA-URA3 plasmid [34], to chromosomally tag the HA epitope to the C-termini of CaMKC1 and CaCEK1 in relevant strains. Their genotypes were confirmed by PCR (Additional file 1: Figure S2C and S2D).

\section{Co-localization of GDT1-GFP and PMR1-HA proteins}

Cells of the WJCA111 strain was grown to log-phase in SD-URA-HIS medium before they were treated with $100 \mathrm{mM} \mathrm{CaCl}{ }_{2}$ or $1 \mathrm{mM}$ EGTA for 2 and $6 \mathrm{~h}$, respectively. Cells were treated with $3.7 \%$ formaldehyde for $10 \mathrm{~min}$ and incubated in fixation buffer $(0.1 \mathrm{M}$ $\mathrm{KH} 2 \mathrm{PO} 4,0.5 \mathrm{M} \mathrm{MgCl} 2,3.7 \%$ formaldehyde, $\mathrm{pH}$ 6.5) for $20 \mathrm{~min}$. Cells were then resuspended in $1 \mathrm{ml}$ buffer 
(0.1 $\mathrm{M} \mathrm{KH}_{2} \mathrm{P}_{4}, 1.2 \mathrm{M}$ sorbitol, $\mathrm{pH}$ 6.5) supplemented with $4 \mu \mathrm{l}$ of beta-mercaptoethanol and $4 \mu \mathrm{l}$ of $5 \mathrm{mg} \mathrm{ml}^{-}$

${ }^{1}$ Zymolyase $20 \mathrm{~T}$ (Seikagaku Biobusiness), and incubated at $37{ }^{\circ} \mathrm{C}$ for $20 \mathrm{~min}$. Spheroplasts were washed twice with $1 \mathrm{ml}$ of PBS buffer, and suspended in $100 \mu \mathrm{l}$ of PBS supplemented with 0.05\% Tween 20 (PBST).

BSA of $400 \mu \mathrm{g} \mathrm{ml}^{-1}$ was added to the spheroplast mixture, and incubated for 20 min before mouse anti-HA antibodies was added at a dilution of 1:500. The mixture was incubated for $2 \mathrm{~h}$, and washed twice with PBST before goat anti-mouse IgG conjugated to Alexa Fluor 555 (Invitrogen, USA) was added. The mixture was incubated in dark for $45 \mathrm{~min}$ before spheroplasts were collected, washed three times, and visualized under a Nikon 80i microscope equipped with DS-U2 CCD. The images were acquired at $1000 \times$ and processed using the NIS - ELEMENTS F3.0 software.

\section{Co-localization of GDT1-GFP protein and Golgi-tracker red dye}

For Golgi apparatus labeling, the pmr1/pmr1 GDT1 -GFP/gdt1 cells were grown to log-phase in SD-URA, harvested, washed twice with PBS, and suspended in 200 $\mu \mathrm{l}$ PBS supplemented with $4 \mu \mathrm{l}$ beta-mercaptoethanol and $15 \mathrm{U}$ lyticase enzyme (Sigma). Cells was incubated at $37^{\circ} \mathrm{C}$ for $40 \mathrm{~min}$ to partially digest the cell wall, and were washed once with PBS and suspended in $200 \mu \mathrm{l}$ PBS before they were mixed with $2 \mu \mathrm{l}$ Golgi-Tracker Red dye $\left(33.3 \mathrm{mg} \mathrm{ml}^{-1}\right.$ ) (Beyotime Institute of Biochemistry, China) and incubated at $4{ }^{\circ} \mathrm{C}$ for $30 \mathrm{~min}$. Cells were then washed twice and incubated in $1 \mathrm{ml} \mathrm{SD-URA}$ at $30{ }^{\circ} \mathrm{C}$ for $30 \mathrm{~min}$, before they were visualized by the Nikon $80 \mathrm{i}$ fluorescent microscope.

\section{RNA extraction and qRT-PCR assays}

Total RNA was extracted as described previously (12). Contaminated genomic DNA in the reverse transcription products was examined by PCR of 35 cycles using a pair of primers CaACT1-g-UP and CaACT1-g/m-DOWN flanking the intron of the C. albicans ACT1 gene. Real-time qPCR was performed in the CFX96 ${ }^{\mathrm{mm}}$ Real-Time System I (BIO-RAD) using SYBR Premix EX Taq $^{\text {tix }}$ II (TAKARA Biotechnology, China). All assays were performed in duplicate. For quantification, the abundance of each gene was determined relative to the transcript of CaACT1.

\section{Transcript profiling and data analysis}

Total RNA samples were extracted from the wild type CAI4, the $g d t 1 / g d t 1$, the $p m r 1 / p m r 1$, and the $g d t 1 / g d t 1$ pmr1/pmr1 mutants grown to log phase in SD-URA at $30{ }^{\circ} \mathrm{C}$. RNA integrity was evaluated using an Agilent 2100 Bioanalyzer (Agilent Technologies, USA). RNA-seq libraries were constructed using Illumina's TruSeq RNA
Sample Preparation Kit (Illumina Inc., USA). RNA sequencing, data analysis and sequence assembly were performed by Beijing BioMarker Technologies (Beijing, China). Preparation of the paired-end libraries and sequencing were performed following standard Illumina methods and protocols. The mRNA-seq library was sequenced on the Illumina Hiseq 2500 and Illumina Genome Analyzer system.

To obtain high-quality clean read data for de novo assembly, raw reads from mRNA sequencing were filtered by discarding the reads with adaptor contamination, masking low-quality reads with ambiguous ' $\mathrm{N}$ ' bases and removing reads in which more than $10 \%$ bases had a Q-value $<20$. Clean reads were assembled into full-length transcriptome from RNA-Seq data with the reference genome (http://www.candidagenome.org/).

\section{Digital analysis of gene expression}

Gene expression levels were measured as numbers of reads, and normalized with RPKM in RNA-Seq analyses as described [36]. Differentially expressed genes were identified in pair-wise comparison with the IDEG6 software [37], and all statistical test results were corrected for multiple testing with the Benjamini-Hochberg false discovery rate $(\mathrm{FDR}<0.01)$. Gene transcripts were considered to be significantly differentially expressed if the adjusted $P$ value was $<0.001$ and there was at least a two-fold change ( $>1$ or $<-1$ in $\log 2$ ratio value) in PKM between two libraries.

\section{Semi-quantitation of gene expression levels by RT-PCR}

To confirm the RNA-sequencing data, we carried out semi-quantitative RT-PCR with reverse transcription products that were treated to remove their contaminated genomic DNA. RT-PCR was carried out as described previously [12]. PCR products were separated on agarose gel and stained with ethidium bromide. DNA contents in all lanes of the gel were quantified and analyzed using the Bio-Rad Gel DocTM XR+ System and the Image Lab software (Version 4.0.1). Relative levels of target gene transcripts in each strain were calculated using CaPGK1 as the internal control.

\section{Statistical analysis}

Significant differences were analysed by GraphPad Prism version 4.00. $P$ values of $<0.05$ were considered to be significant.

\section{Results}

CaGDT1 complements the function of SCGDT1 in cell wall stress

As reported previously [30], expression of CaGDT1 in the $S$. cerevisiae vector, pHAC181, fully suppressed the sensitivity of the Scgdt1 single-gene deletion mutant to 
$0.6 \mathrm{M}$ and $0.7 \mathrm{M} \mathrm{CaCl}_{2}$ as well as the sensitivity of the Scgdt1/Scpmr1 double-gene deletion mutant to $0.4 \mathrm{M}$ $\mathrm{CaCl}_{2}$ (Additional file 1: Figure S1A). In addition, expression of CaGDT1 reverted the sensitivity level of the Scgdt1/Scpmr1 double-gene deletion mutant to that of the Scpmr1 single-gene deletion mutant under higher concentrations of $\mathrm{CaCl}_{2}(0.6 \mathrm{M}$ and $0.7 \mathrm{M}$ ) (Additional file 1: Figure S1A). Therefore, CaGDT1 is a functional homolog of ScGDT1 in calcium stress [30]. Although $S$. cerevisiae cells lacking ScGDT1 were not sensitive to $5 \mathrm{mM}$ EGTA, $0.4 \mathrm{M} \mathrm{CaCl}_{2}, 100 \mu \mathrm{g} \mathrm{ml}^{-1}$ Congo red (CR) and $50 \mu \mathrm{g} \mathrm{ml}^{-1}$ Calcofluor white (CFW) [7], we found that deletion of ScGDT1 increased the sensitivity of cells lacking ScPMR1 to all these reagents (Additional file 1: Figure S1A). Expression of CaGDT1 reverted the sensitivity level of the $S c g d t 1 / S c p m r 1$ double-gene deletion mutant to that of the Scpmr1 single-gene deletion mutant under these cell-wall stress conditions (Additional file 1: Figure S1A). Taken together, these data demonstrate that CaGdt1 complements the function of ScGdt1 in the response of $S$. cerevisiae cells to cell-wall stress.

\section{CaGDT1 shows genetic interactions with CaPMR1 in the} response to cell wall and ER stress

Since mutations of human TMEM165, the CaGdt1 homolog, affect the glycosylation pathway [25, 38], we tested cells lacking CaGDT1 against cell wall and ER stresses. Surprisingly, C. albicans cells lacking CaGDT1 did not show significant alteration in their sensitivity to CR, CFW, caffeine and tunicamycin (Fig. 1a).

Unlike ScGDT1, C. albicans cells lacking CaGDT1 were not sensitive to $0.7 \mathrm{M} \mathrm{CaCl}_{2}$ (Fig. 1a; Additional file 1: Figure S1A; [25]). However, ScGDT1 genetically interacts with ScPMR1 in the calcium sensitivity of $S$. cerevisiae cells [25]. We next investigated possible interactions between CaGDT1 and CaPMR1 in cell wall stress. As reported previously [10], cells lacking CaPMR1 were hypersensitive to CR, CFW, caffeine and tunicamycin (Fig. 1a and b). Further deletion of CaGDT1 increased the sensitivity of cells lacking CaPMR1 to CR, $\mathrm{CFW}$, caffeine and tunicamycin, which could be reversed by the introduction of the CaGDT1 gene (Fig. 1a and b). These results demonstrate that $C a G D T 1$ has an additive effect on CaPMR1 in the response of $C$. albicans cells to cell wall and ER stresses.

\section{Calcineurin function is required for $C$. albicans cells in response to cell wall stress}

Further deletion of CaGDT1 led cells lacking CaPMR1 hypersensitive to cyclosporine A (CsA) and FK506, specific inhibitors of calcineurin, in YPD medium with or without cell wall stress (Fig. 1b; Additional file 1: Figure S1B). This indicates that normal growth of C. albicans cells lacking both $C a G D T 1$ and $C a P M R 1$ requires the calcineurin function.

The homozygous mutant for CaGDT1 became hypersensitive to CR and CFW in the presence of $50 \mu \mathrm{g} \mathrm{ml}^{-1}$ $\mathrm{CsA}$, and its sensitive degree was comparable to that of C. albicans cells lacking both CaGDT1 and CaPMR1 on YPD plates containing these reagents without CsA (Compare Fig. $1 \mathrm{~b}$ to a). Furthermore, addition of CsA in YPD plates made $C$. albicans cells more sensitive to $C R$ and CFW independent of CaGDT1 and CaPMR1 (Compare Fig. $1 b$ to a). This suggests that calcineurin function is additive to the overlapping function between CaGdt1 and CaPmr1 in the response of C. albicans cells to cell wall stress.

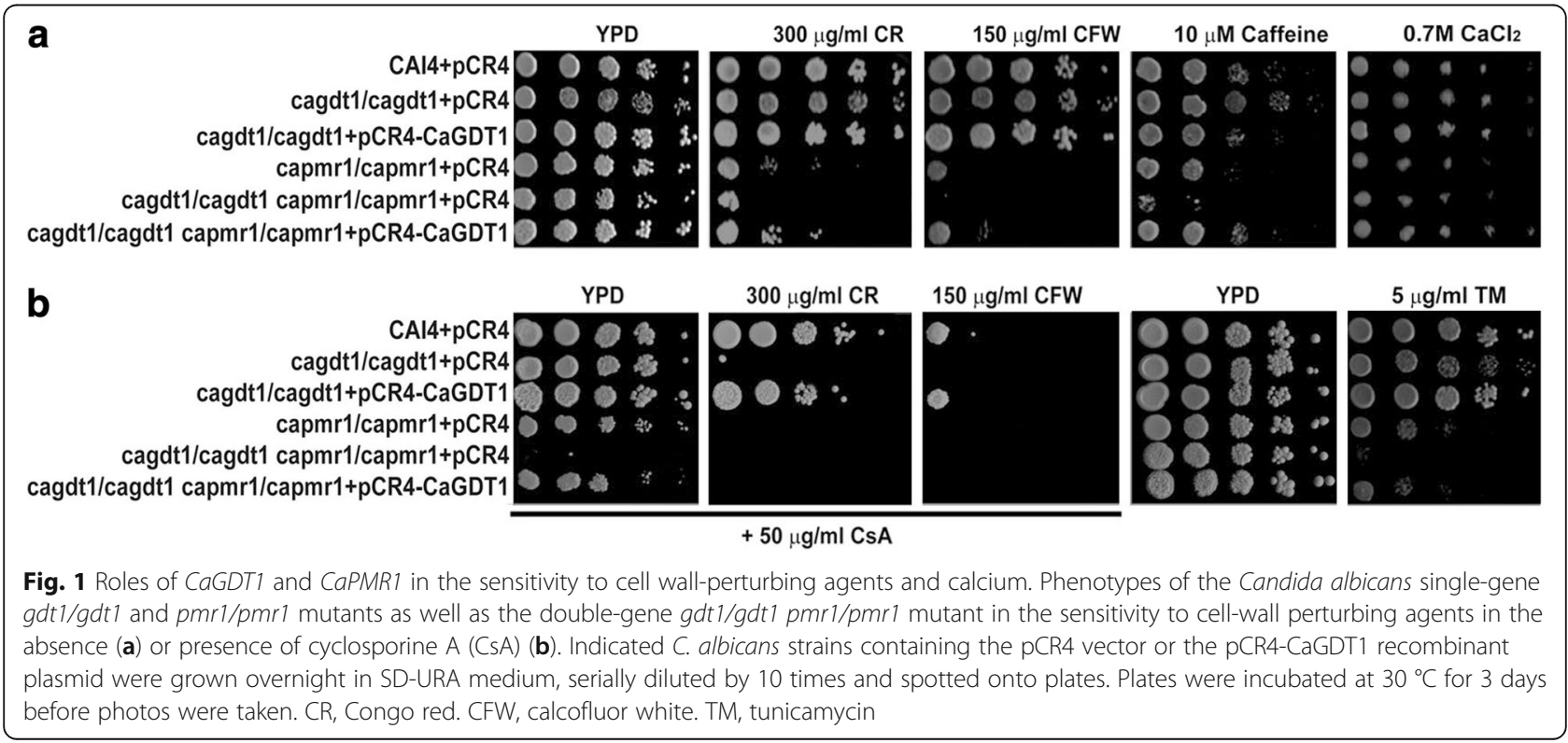


Inhibition of calcineurin promotes cell death and disrupts cell wall and vacuolar integrity of cells lacking both

\section{CaGDT1 and CaPMR1}

To further investigate the growth defect of $C$. albicans cells lacking CaGDT1 and CaPMR1 in the presence of CsA, we determined their clonogenic survival ability by measuring their colony-forming units. In response to 25 $\mu \mathrm{g} \mathrm{ml}{ }^{-1} \mathrm{CsA}$ in YPD medium, cells of the $g d t 1 / g d t 1$ pmr1/pmr1 mutant lost their viability in both time-dependent and dose-dependent fashions (Fig. 2a and $b)$. However, CsA treatment of the wild type did not affect its viability (Data not shown). This indicates that CsA promotes the death of cells lacking both $C a G D T 1$ and CaPMR1.

Compared to untreated cells (Fig. 2c), most of cells treated with $25 \mu \mathrm{g} \mathrm{ml}^{-1} \mathrm{CsA}$ for $8 \mathrm{~h}$ were abnormal in their internal structures (Fig. 2d), and appeared to be flakes in culture solution (Fig. 2e). To examine their cell wall integrity, we co-stained these cells with Annexin V-FITC (green fluorescence) and propidium iodide (red fluorescence), which measure externalization of phosphatidylserine and loss of membrane integrity of yeast cells, two indicators of cell death $[39,40]$. Only a few of the wild-type and the mutant cells untreated with CsA were stained (Fig. 2f). Comparing to the CsA-treated wild-type with only a few of stained cells, most of mutant cells treated with CsA were stained, by these two dyes (Fig. 2g), indicating susceptible cell walls of CsA-treated mutant cells for an easy entry of these dyes.

To understand the nature of the abnormal intracellular compartments in CsA-treated cells lacking both CaGDT1 and CaPMR1 (Fig. 2d), we examined the integrity of their vacuoles with the dye FM4-64 [33]. Untreated wild-type and mutant cells showed a uniform
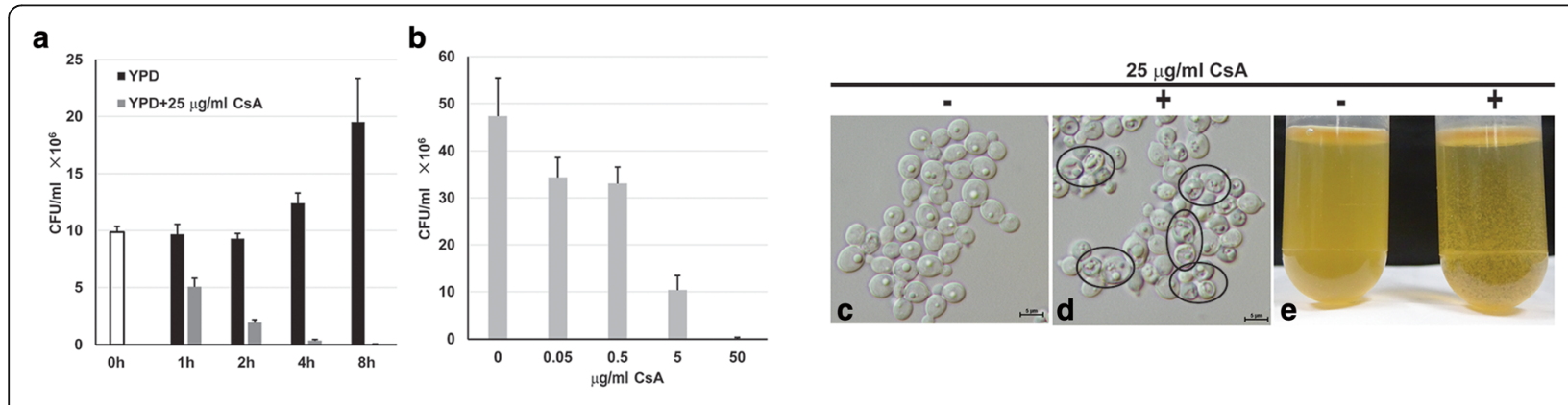
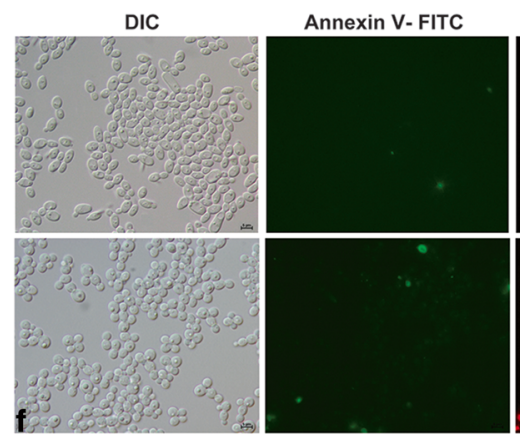

Propidium iodide

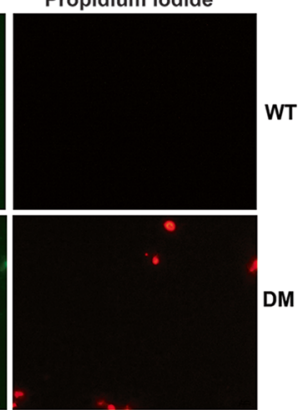

FM-64

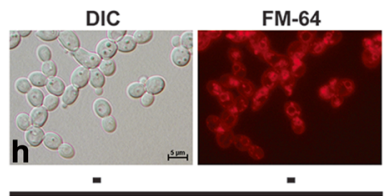

DM

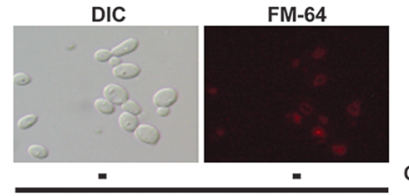

WT

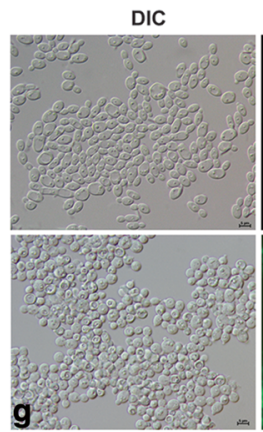

Annexin V- FITC
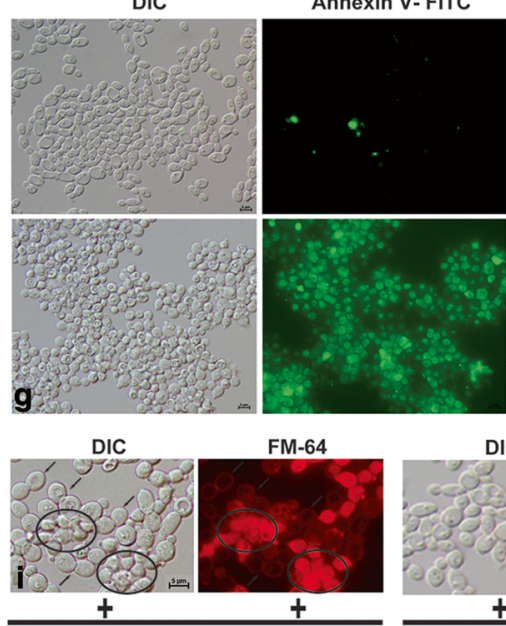

DM
Propidium iodide

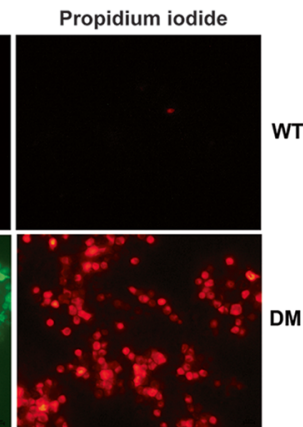

DIC

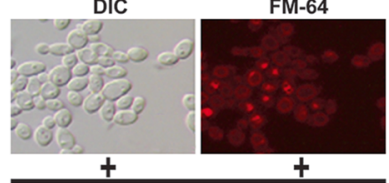

WT

Fig. 2 Calcineurin function is essential for cell survival and integrity of C. albicans cells lacking both CaGDT1 and CaPMR1. Quantification of clonogenic survival of cells treated with CsA for different time (a) and different concentrations (b) as indicated. Clonogenic survival was determined by plating cells onto YPD plates, and colony-forming unit (CFU) was counted manually. Data are means of three independent experiments. Empty bar indicates the colony-forming unit (CFU) of the cell culture immediately before the CsA treatment. Black bars and grey bars represent CFUs of cell cultures not treated and treated with $25 \mu \mathrm{g} \mathrm{m} \mathrm{l}^{-1}$ CsA, respectively. Morphology of cells untreated (c) and treated with CsA for $8 \mathrm{~h}$ (d). e Cell cultures untreated (left test tube) and treated with CsA for $8 \mathrm{~h}$ (right test tube). Representative epifluorescent micrographs of cells untreated $(\mathbf{f})$ and treated with CsA for $8 \mathrm{~h}(\mathbf{g})$ after being co-stained with both Annexin V-FITC and propidium iodide. Epifluorescent micrographs of cells untreated (h) and treated with CsA for $4 \mathrm{~h}(\mathbf{i})$, after being incubated with the vacuole indicator dye FM4-64 for 30 min. The wild-type (WT) and the double-gene gdt1/gdt1 pmr1/pmr1 mutant (DM) were cultured at $30{ }^{\circ} \mathrm{C}$ in YPD to log phase before they were treated with CsA of $25 \mu \mathrm{g} / \mathrm{ml}$ for these experiments. Cells with normal cell morphology but without intracellular FM4-64 staining are indicated with arrows, while cells with abnormal internal structures are circled 


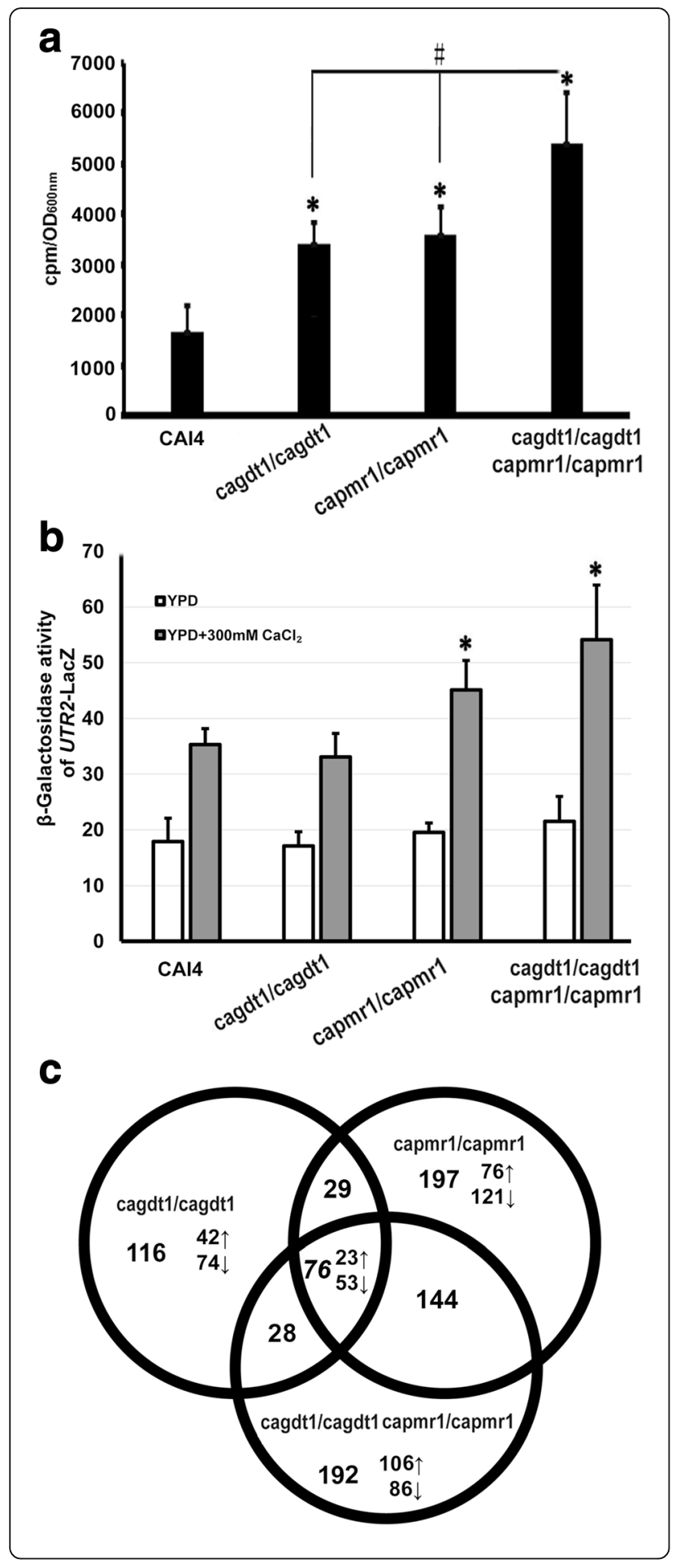

Fig. 3 Function of CaGDT1 and CaPMR1 in calcium uptake, calcineurin signaling and gene expression. $\mathbf{a} \mathrm{Ca}^{2+}$ accumulation in C. albicans cells lacking CaGDT1 and/or CaPMR1. Cells of the wild type (CAI4), the gdt1/ gdt1 mutant, the pmr1/pmr1 and the gdt1/gdt 1 pmr1/pmr1 mutant were grown to log-phase in YPD medium in the presence of ${ }^{45} \mathrm{Ca}^{2+}$, and $\mathrm{OD}_{600 \mathrm{~nm}}$ values and intracellular ${ }^{45} \mathrm{Ca}^{2+}$ levels of these strains were measured. $\mathbf{b} \beta$-galactosidase activities of UTR2-lacZ reporter in the wild type and the three mutant cells in the absence or presence of $300 \mathrm{mM}$

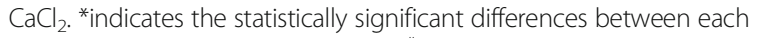
mutant and the wild-type $(p<0.05)$. " indicates the significant difference between the gdt1/gdt1 pmr1/pmr1 mutant and each of its two single-gene deletion mutants $(<0.05)$. c Shared differentially expressed genes (DEGs) between cells lacking the gdt1/gdt 1, the pmr1/ pmr1 or the gdt1/gdt1 pmr1/pmr1 mutants. DEGs for each mutant are obtained from its comparison to the wild type, which include 249 $(=116+29+76+28)$ genes for the gdt 1/gdt1, $446(=197+29+76+$ 144) genes for the $\mathrm{pmr} 1 / \mathrm{pmr} 1$ mutant, and $440(=192+28+76+144)$ genes for the gdt1/gdt1 pmr1/pmr1 mutant, respectively. Total numbers of shared DEGs between two, or among three, mutants are indicated

staining pattern of vacuoles, indicating normal endocytosis and enrichment of FM4-64 in the vacuolar membrane (Fig. 2h). Wild-type cells treated with CsA showed a uniform staining pattern, while mutant cells treated with CsA exhibited various staining patterns (Fig. 2i), including cells with normal intracellular compartments and no intracellular staining, indicating their lost ability of transporting FM4-64 through endocytosis, and cells with abnormal intracellular compartments and strong whole-cell staining, indicating their disrupted vacuolar structures. Taken together, these results suggest that calcineurin function is essential for the cell survival as well as the cell wall and vacuolar integrity of cells lacking both $C a G D T 1$ and $C a P M R 1$.

Calcium uptake and activation of the calcium/calcineurin signaling in C. albicans cells lacking CaGDT1 and CaPMR1 Although deletion of CaGDT1 did not alter the sensitivity of $C$. albicans cells to calcium stress, we showed that CaGDT1 complemented the function of ScGDT1 in calcium stress ([30]; Additional file 1: Figure S1A). Both ScGdt1 and its human ortholog TMEM165 are involved in the regulation of cytosolic $\mathrm{Ca}^{2+}$ and $\mathrm{pH}$ homeostasis [7]. We next measured the uptake of ${ }^{45} \mathrm{Ca}^{2+}$ in mutants for CaGDT1 and/or CaPMR1. As compared to the wild type, both the $g d t 1 / g d t 1$ and the $p m r 1 / p m r 1$ mutants exhibited similar high levels of ${ }^{45} \mathrm{Ca}^{2+}$ uptake in YPD medium, while their double-gene mutant showed an even higher level of ${ }^{45} \mathrm{Ca}^{2}$ uptake (Fig. 3a). Increased calcium uptake was also observed for cell lacking ScPMR1 [41]. These results suggest that CaGdt1 and CaPmr1 have additive functions in the regulation of calcium homeostasis. This is consistent with observations for ScGdt1 and ScPmr1 in S. cerevisiae [7, 42]. 
We next examined activation levels of the calcium/calcineurin signaling in these mutants with the lac $\mathrm{Z}$ reporter of CaUTR2, a downstream target of CaCrz1 [43]. There was no significant difference in the lacZ activity between the wild type and each of three mutants in YPD medium (Fig. 3b). In the presence of $0.2 \mathrm{M} \mathrm{CaCl}_{2}$, both the pmr1/pmrl and the double-gene mutants showed higher lac Z activities than, but the $g d t 1 / g d t 1$ mutant showed a similar lacZ activity to, the wild type (Fig. 3b). These CaUTR2p::lacZ activity results agree with our transcriptomic profiling data on the transcript levels of CaUTR2 (CAWG_02505) in these mutants and the wild type (SuppInfo 1 and 2 [GEO Accession number: GSE100737]). Taken together, these data indicate that CaPmr1 is the major controller of calcium homeostasis in C. albicans, which in consistent with observations on ScPmr1 in S. cerevisiae [7, 42].

\section{CaGdt1 plays a role in the CaCek1-mediated, but not} CaMkc1-mediated, cell wall integrity signaling Deletion of CaPMR1 activates the Mkc1-mediated CWI signaling [10]. Since deletion of CaGDT1 increased the sensitivity of cells lacking CaPMR1 to cell wall stresses (Fig. 1a), we examined the effect of CaGDT1 deletion on CWI signaling. We chromosomally tagged the HA epitope to the C-terminus of the CaPKC1 allele and the CaMKC1 allele, respectively, in the wild type CAI4, the WJCAG22 ( $g d t 1 / g d t 1)$, the NGY98 (pmr1/pmr1) and the WJCAG25 ( $g d t 1 / g d t 1$ pmrl/pmrl) strains (Additional file 1: Figure S2A, $2 \mathrm{C}$ and $2 \mathrm{D}$ ). In YPD medium, phosphorylation levels of the wild type CaMkc1 (or the HA-tagged CaMkc1-HA fusion) were similar between the wild type and the $g d t 1 / g d t 1$ strains in the absence or presence of $50 \mu \mathrm{g} \mathrm{ml}^{-1} \mathrm{CFW}$ (Fig. 4a). As reported previously [10], phosphorylation levels of CaMkc1 (or CaMkc1-HA) increased with similar degrees in both the pmr1/pmr1 and the $g d t 1 / g d t 1$ pmr1/pmr1 mutants as compared to the wild type (Fig. 4a). Similar patterns for CaMkc1 phosphorylation levels were also observed in C-terminally HA tagged CaCEK1 strains (Fig. 4b). These results indicate that $\mathrm{CaPmr1}$ does, but CaGdt1 does not, play a role in the CaMkc1-mediated CWI signaling -.

The CaCek1-mediated CWI signaling is also involved in cell wall construction [18]. Phosphorylated CaCek1 and CaCek1-HA) were not detected in both the wild type and the $g d t 1 / g d t 1$ strains, while the $g d t 1 / g d t 1$ pmr1/pmr1 mutant showed a higher level of phosphorylated CaCek1 and CaCek1-HA than the pmr1/pmr1 mutant in the absence or presence of CFW (Fig. 4b). Similarly, in C-terminally HA tagged CaMKC1 strains, the $g d t 1 / g d t 1$ pmr1/pmr1 mutant showed a higher level of phosphorylated CaCek1 than the pmr1/pmr1 mutant in the absence or presence of CFW, while phosphorylated $\mathrm{CaCek} 1$ was detected at very low levels in both the wild type and the $g d t 1 / g d t 1$ strains, with a slightly higher level in the latter (Fig. 4a). Taken together, these data suggest that CaGdt1 and CaPmr1 are both involved in the activation of CaCek1-mediated CWI signaling independent of cell wall stress.

\section{CaGdt 1 is localized in the Golgi apparatus but at distinct sites from CaPmr1}

To determine the subcellular localization of CaGdt1, we chromosomally tagged the green florescent protein

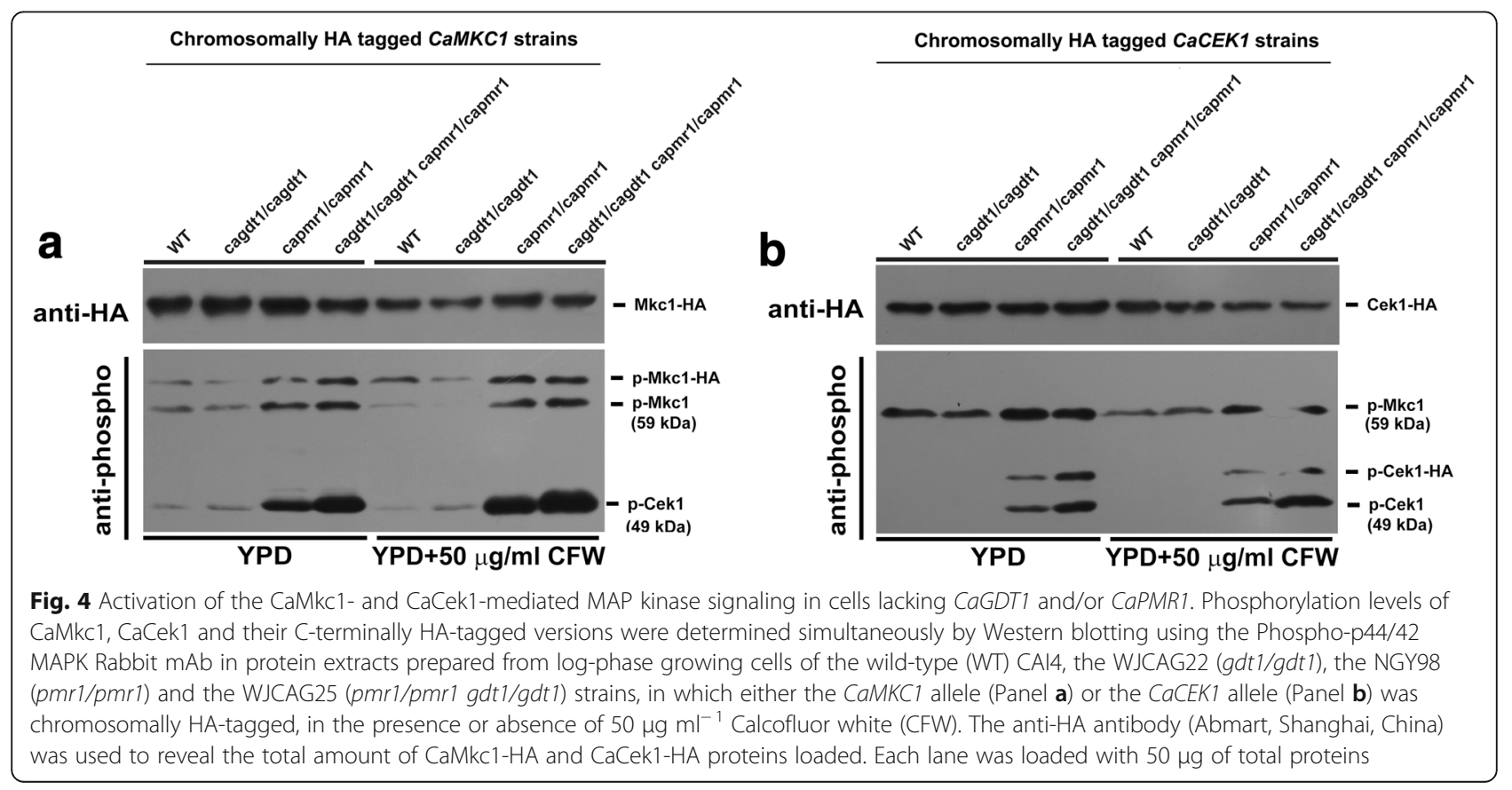


(GFP) to the C-terminus of CaGdt1 in the heterozygous mutant for CaGDT1 generating WJCA102 (CAI4 pmr1pmr1 GDT1-GFP/gdt1) (Additional file 1: Figure S2). Like the pmr1/pmr1 mutant, the WJCA102 mutant was not sensitive to CsA, while the pmr1/pmr1 gdt1/ gdt1 mutant was (Fig. 5a). This indicates that the CaGDT1-GFP allele is functional. In log-phase growing cells of WJCA102, CaGDT1-GFP was colocalized with the Golgi Tracker Red dye (Fig. 5b).

Similarly, we constructed the WJCA111 (RM1000 PMR1/PMR1::HA-HIS1 GDT1/GDT1::GFP-URA3) strain to examine the colocalization between CaGdt1 and CaPmr1 (Data not shown). Through indirect immunofluorescent approach, we found that the CaGDT1-GFP protein was not colocalized with the CaPMR1-HA in log-phase growing WJCA111 cells (Fig. 5c). It should be noted that there was a discrepancy in CaGDT1-GFP localization between Fig. $5 \mathrm{~b}$ and c, which could be due to the difference in sample processing for florescent microscopy as described in the Methods section. In response to depletion of extracellular calcium (1 mM EGTA treatment) or high levels of extracellular calcium, the CaGDT1-GFP protein was also not colocalized with the CaPMR1-HA in WJCA111 cells (Additional file 1: Figure S3). Taken together, these results indicate that
CaGdt1 is present in the Golgi apparatus but at distinct sites from CaPmr1 in C. albicans.

\section{Transcriptomic profiling of cells lacking CaGDT1 and/or CaPMR1}

To help us further understand functions of CaGdt1 and CaPmr1, we carried out transcript profiling for the wild type CAI4, the $g d t 1 / g d t 1$, the $p m r 1 / p m r 1$, and the $g d t 1 /$ gdt1 pmr1/pmr1 mutants, growing in log phase in YPD medium at $30{ }^{\circ} \mathrm{C}$ (GEO accession number: GSE100737). Transcripts of 5901 genes at various expression levels were detected in each of these four strains (SuppInfo 1 [GEO Accession number: GSE100737]). As compared to the wild type, there are 249,446 and 440 differentially expressed genes (DEGs) in the $g d t 1 / g d t 1$, the pmr1/ pmr1 and the $g d t 1 / g d t 1$ pmrl/pmr1 mutants, respectively (Fig. 3c; SuppInfo 2). Deletion of CaGDT1 does not affect the transcript level of CaPMR1, and vice versa (SuppInfo 2).

There are 105 shared DEGs between the $g d t 1 / g d t 1$ and the pmr1/pmr1 mutants, which accounts for $42 \%$ (105/ 249) of total DEGs due to deletion of CaGDT1 or $24 \%$ (105/446) of total DEGs due to deletion of CaPMR1 (Fig. 3c). This indicates that CaGdt1 and CaPmr1 have shared and distinct functions. Furthermore, there are 76 shared DEGs among the $g d t 1 / g d t 1$, the $p m r 1 / p m r 1$ and

\section{a $\quad$ YPD $\quad 200 \mu \mathrm{g} / \mathrm{ml} \mathrm{CR} \quad 100 \mu \mathrm{g} / \mathrm{ml} \mathrm{CFW} \quad 50 \mu \mathrm{g} / \mathrm{ml} \mathrm{CsA}$

\begin{tabular}{|c|c|c|c|c|c|c|}
\hline 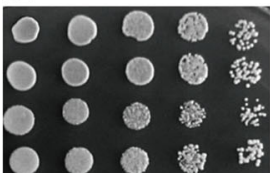 & $\begin{array}{llll}0 & 0 & 0 & 0 \\
0 & 0 & 0 & 0 \\
0 & 0 & 0\end{array}$ & $\begin{array}{l}0 \\
0 \\
0 \\
0\end{array}$ & tis & 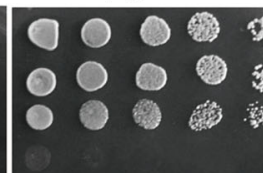 & & $\begin{array}{l}\text { CAI } 4 \\
\text { capmr1/capmr1 } \\
\text { capmr1/capmr1 cagdt1/CaGDT1-GFP } \\
\text { capmr1/capmr1 cagdt1/cagdt1 }\end{array}$ \\
\hline
\end{tabular}
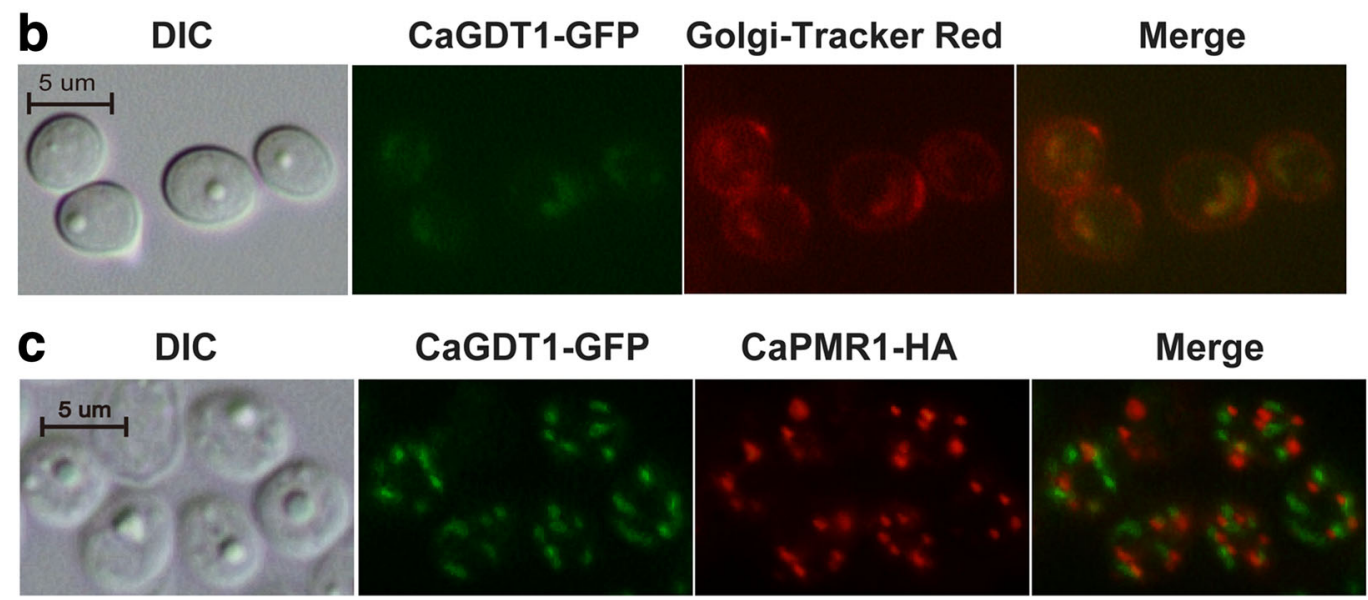

Fig. 5 Subcellular localization of CaGdt1 and its function in virulence. a Functional test of the GDT1-GFP allele in the sensitivity of $C$. albicans cells to Congo red (CR), Calcofluor white (CFW) and cyclosporine A (CSA) in WJCA102 cells (pmr1/pmr1 gdt1/GDT1-GFP). b co-localization of CaGDT1GFP and Golgi-Tracker Red marker in the WJCA102 cells. c Co-localization of CaGDT1-GFP and CaPMR1-HA in WJCA111 cells through indirect immunofluorescent approach. Images of differential interference contrast (DIC), GFP, red florescence derived from Golgi-Track Red dye (b) or from goat anti-mouse lgG conjugated to Alexa Fluor 555 (for CaPMR1-HA protein) (c) and their merged images are presented. Scale bar, 5 m 
the $g d t 1 / g d t 1$ pmr1/pmr1 mutants, with 23 of them being up-regulated and 53 of them being down-regulated (Fig. 3c; Table 3). Using a semi-quantitative RT-PCR approach, we confirmed the transcript levels of selected 15 out of these 76 genes in the wild type, the $g d t 1 / g d t 1$, the pmr1/pmr1 and the $g d t 1 / g d t 1$ pmr1/pmr1 mutants (Additional file 1: Figure S4). The 23 up-regulated DEGs are involved in the cellular transport, including the transporters of long-chain fatty acids (PXA1 and PXA2), the calcium channel $(\mathrm{CCH} 1)$ and the potassium transporter (TRK1) (Table 3). Similarly, a big portion of the 53 down-regulated DEGs are also involved in the cellular transport, with different substrates including amino acids (MUP1, QDR1, ALP1, GNP1, TPO3 and TPO4) [44], lipids (PDR16), nucleosides (CNT) [45], calcium ions (RCH1) [13] and sodium ions (ENA2). In addition, 10 of these down-regulated DEGs are involved in the protein synthesis (Table 3 ). These data suggest that core functions shared by CaGdt1 and CaPmr1 are involved in the regulation of cellular transport of metal ions and amino acids.

CaGdt1 homologs in humans and S. cerevisiae have been shown to regulate glycosylation pathway [25, 27]. In S. cerevisiae, there are two main types of glycosylation, the $N$-linked and the O-linked glycosylation (http:// www.kegg.jp/kegg/pathway.html). The $N$-linked glycosylation is the attachment of the oligosaccharide known as glycan to the amide nitrogen of an asparagine residue of a protein, There are 30 genes involved in the $N$-linked glycosylation in S. cerevisiae, with 20 of them having homologs in C. albicans (Additional file 1: Table S2). Transcript levels of CAWG_02847 (DIE2) and CAWG_03939 (STT3) are up-regulated only in the $g d t 1 / g d t 1$ pmr1/pmr1 mutant, while that of CAWG_04868 (OST3) is up-regulated in both the pmr1/pmr1 mutant and the $g d t 1 / g d t 1$ pmr1/pmr1 mutant, but not in the $g d t 1 / g d t 1$ mutant (Additional file 1: Table S2). The $O$-linked glycosylation is the attachment of a sugar molecule (such as $\mathrm{N}$-acetyl-galactosamine, $\mathrm{N}$-acetylglucosamine and mannose) to an oxygen atom in serine or threonine residue of a protein. There are 13 genes involved in the O-linked glycosylation n S. cerevisiae, with 7 of them showing homologs in C. albicans (Additional file 1: Table S3). Expression of CAWG_05623 (PMT1) and CAWG_04353 (PMT4) is up-regulated only in the $g d t 1 / g d t 1$ pmr1/pmr1 mutant (Additional file 1: Table S3). Furthermore, from the C. albicans genome database we identified 20 genes involved in the CWI pathway based on their homologs in S. cerevisiae (Additional file 1: Table S4) [46]. Only one gene CAWG_01201 (SWI4) was transcriptionally upregulated in each of three mutants, while expression of the gene CAWG_05506 (BEM2) was down regulated in the pmr1/pmr1 mutant, but not affected in both the $g d t 1 / g d t 1$ mutant and the $g d t 1 / g d t 1$ pmrl/pmr1 mutant (Additional file 1: Table S4).

\section{Discussion}

Congenital disorders of glycosylation (CDG) are rare inherited diseases causing severe growth and psychomotor retardations in patients, with most of their genetic defects affecting the glycosylation process. The human ortholog for yeast ScGdt1, TMEM165, is one of these CDG-associated Golgi proteins and might function as a $\mathrm{Ca}^{+} / \mathrm{H}^{+}$antiporter and/or a $\mathrm{Mn}^{2+}$ transporter in the Golgi $[26,27,46-48]$. In line with these findings, we have provided evidence that the $C$. albicans functional ortholog of ScGdt1, CaGdt1, plays a compensatory role for CaPmr1, the high affinity $\mathrm{Ca}^{2+} / \mathrm{Mn}^{2+}$ P-type ATPase that is required for $\mathrm{Ca}^{2+}$ and $\mathrm{Mn}^{2+}$ transport into the Golgi and involved in $\mathrm{Ca}^{2+}$ dependent protein sorting processing, in the regulation of calcium homeostasis and cell wall stress. In addition to the role of CaPmr1 in activation of Mkc1-mediated CWI signaling [10], we show that deletion of CaPMR1 activates the Cek1-mediated CWI signaling (Fig. 4). This agrees with the function of Cek1 in cell wall construction [18]. In contrast, deletion of CaGDT1 alone does not affect the Mkc1-mediated CWI signaling, but activates the Cek1-mediated signaling. Although C. albicans cells lacking CaPMR1 are not sensitive to SDS [10], which targets both the cell wall and the plasma membrane, deletion of CaGDT1 renders C. albicans cells lacking CaPMR1 sensitive to SDS and more sensitive to hygromycin B (Additional file 1: Figure S1D). We also demonstrate that CaGdt1 and CaPmr1 are present at distinct sites in the Golgi apparatus, which is not affected by the calcium depletion or high levels of calcium in the extracellular environment. CaGdt1 is a functional homolog of ScGdt1 in the response of S. cerevisiae cells to calcium and cell wall stresses (Additional file 1: Figure S1; 30). Therefore, our data supports the hypothesis that CaGdt1 together with human TMEM165 and ScGdt1 might form a new group of Golgi-localized $\mathrm{Ca}^{2+} / \mathrm{H}^{+}$exchangers [6].

As the central player in the calcium signaling, calcineurin has been shown to play a role in early synaptic dysfunction and neuronal death in mammalian cells [49]. In addition, ER stress can induce nonapoptotic cell death in yeasts, which can be blocked by the action of calcineurin [50]. Consistently, we show here that calcineurin function is required for the growth as well as the cell wall and vacuolar integrity of cells lacking both $C a G D T 1$ and CaPMR1. Therefore, the calcium/calcineurin signaling, CaGdt1 and CaPmr1 work together to regulate the integrity of both the external cell wall and the intracellular vacuole in C. albicans.

Deletion of $S c G D T 1$ increases the calcium sensitivity of $S$. cerevisiae cells lacking ScPMR1, while deletion of 
CaGDT1 does not affect the calcium sensitivity of $C$. albicans cells lacking CaPMR1 (Fig. 1a; Additional file 1: Figure S1A). It is interesting to note that although deletion of CaGDT1 increases the intracellular calcium concentration in C. albicans cells lacking CaPMR1 and elevates their activation levels of the calcium/calcineurin signaling, it does not affect their calcium sensitivity (Figs. 1 and 3a and b). Nevertheless, deletion of CaGDT1 increases the sensitivity of $C$. albicans cells lacking CaPMR1 to cell wall and ER stresses (Fig. 1). Therefore, the calcium homeostasis in the ER/Golgi apparatus is mainly involved in the regulation of the cell wall integrity. This is further supported by our recent observation on the deletion effect of CaRCH1, encoding a negative regulator of calcium uptake on the plasma membrane, on cells lacking CaPMR1 [51]. In addition, normal growth of $C$. albicans cells lacking both CaGDT1 and CaPMR1 is, but that of $S$. cerevisiae cells lacking both ScGDT1 and ScPMR1 is not, sensitive to the inhibition of calcineurin function (Fig. 1b; Additional file 1: Figure S1C). Furthermore, CaGdt1 and CaPmr1 localize at different sites of the Golgi compartment in C. albicans, irrespective of alterations in extracellular calcium levels (Fig. 5; Additional file 1: Figure S3). In contrast, ScGdt1 and ScPmr1 are co-localized in the Golgi compartment of S. cerevisiae cells [6]. This difference in the relative localization between Gdt1 and Pmr1 might partially contribute to the differential response of cells lacking both GDT1 and PMR1 to the inhibition of calcineurin in these two microorganisms.

To further investigate the mechanism by which both CaGdt1 and CaPmr1 regulate the survival of C. albicans cells, we have examined the transcriptomic profiles of $C$. albicans cells lacking CaGDT1 and/or CaPMR1. Cells lacking CaGDT1 or CaPMR1 share a significant part of DEGs (Fig. 3c), suggesting that CaGdt1 and CaPmr1 have both shared and distinct functions in C. albicans cells. This is consistent with their distinct localizations in the Golgi compartments of C. albicans cells. We have shown that 192 DEGs are exclusively present in the gdt1/gdt1 pmr1/pmr1 mutant (Fig. 3c). Functions of these genes should be responsible for the unique phenotypes of $C$. albicans cells lacking both CaGDT1 and CaPMR1. Some of these genes might be regulated by the calcium signaling, so inhibition of their transcription by CsA might be responsible for the failure of $C$. albicans cells lacking both CaGDT1 and CaPMR1 to survive in the presence of CsA. As compared to the wild type cells, cells lacking CaGDT1, CaPMR1 or both share 76 DEGs, and most of them involved in the protein synthesis and the transport of amino acids, lipids and nucleosides are down-regulated (Table 3) This might explain why $C$. albicans cells lacking CaGDT1 and/or CaPMR1 grow slower than the wild type (Additional file 1: Figure S5).
During N-linked glycosylation, an oligosaccharide chain is assembled on the carrier molecule dolichyl pyrophosphate in the following order: 2 molecules of $\mathrm{N}$-acetylglucosamine (GlcNAc), 9 molecules of mannose, and 3 molecules of glucose. DIE2 encodes an alpha-1,2 glucosyltransferase that catalyzes the addition of the third glucose moiety [52]. This 14-residue oligosaccharide core is then transferred by the oligosaccharyl transferase complex (OST complex), consisting of nine ER integral membrane protein subunits Ost1-6, Stt3, Swp1 and Wbp1, to an asparagine residue on a nascent prolylpeptide in the ER. As this protein progresses through the Golgi apparatus, its oligosaccharide core is modified by trimming or extension. As a result, a diverse array of $\mathrm{N}$-glycosylated proteins is generated [52, 53]. STT3 is an essential gene, and its conditional mutants are defective in cell wall biosynthesis [54]. On the other hand, protein O-mannosylation (POM) is an evolutionarily conserved, essential posttranslational modification that impacts a variety of cellular processes in both fungi and mammals, which is initiated at the ER by a family of dolichyl phosphate mannose-dependent protein O-mannosyltransferases (PMTs). PMTs transfer mannose residues from dolichyl phosphate-D-mannose to protein seryl/threonyl residues. The POM is essential for yeast cell wall integrity $[55,56]$. In S. cerevisiae, the PMT family is highly redundant (Pmt1-Pmt6) and is classified into three subfamilies, PMT1, PMT2, and PMT4, which mannosylate distinct target proteins [56]. In the present study, we have shown that lack of CaGDT1 and CaPMR1 upregulates the expression of three N-linked glycosylation genes CaDIE2, CaOST3 and CaSTT3 as well as two major O-linked glycosylation genes CaPMT1 and CaPMT4 (Additional file 1: Tables S2 and S4). Since the activation level of the calcium/ calcineurin signaling is significantly elevated due to deletion of CaGDT1 and CaPMR1, our current results indicate that expression of these six glycosylation genes might be under control of the transcription factor CaCrz1. In this way, the defect in cell wall integrity due to deletion of CaGDT1 and CaPMR1 could be compensated by enhanced glycosylation process, specifically the increased biosynthesis of the cell wall beta1,6-glucan [54].

Chitin is an essential component of the fungal cell wall, and $C$. albicans has four chitin synthases, two class I enzymes encoded by $\mathrm{CaCHS} 2$ and $\mathrm{CaCHS} 8$, one class II enzyme encoded by $\mathrm{CaCHS1}$ and one Class IV enzyme encoded by $\mathrm{CaCHS3}$. All four genes are stimulated by CFW treatment. In addition, only expression of CaCHS2 and CaCHS8 is mediated by CaMkc1-mediated CWI signaling [57]. Our transcript profiling data indicates that expression of both CHS1 (CAWG_05611) and CHS8 (CAWG_02407) was not affected due to deletion of CaGDT1 and/or CaPMR1. CHS2 (CAWG_02178) was up regulated in all three mutants, while $\mathrm{CHS3}$ (CAWG_00138) was only up regulated in the pmrl/ 
Table 3 List of shared 76 differentially expressed genes (DEGs) due to deletion of CaGDT1, CaPMR1 or both of them

\begin{tabular}{|c|c|c|c|c|c|c|c|}
\hline Systematic name & Standard name & Systematic name & Standard name & Systematic name & Standard name & Systematic name & Standard name \\
\hline \multicolumn{8}{|l|}{ Up-regulated (23) } \\
\hline \multicolumn{8}{|l|}{ Metabolism } \\
\hline CAWG_02178 & CHS2 & CAWG_05663 & LIP8 & CAWG_05893 & BLM3 & CAWG_06046 & IPK2 \\
\hline \multicolumn{8}{|l|}{ Transcription } \\
\hline CAWG_01201 & SWI4 & CAWG_03966 & SRD1 & & & & \\
\hline \multicolumn{8}{|c|}{ Cellular transport, transport facilities and transport routes } \\
\hline CAWG_00232 & PXA2 & CAWG_01394 & PXA1 & CAWG_01264 & $\mathrm{CCH} 1$ & CAWG_02805 & HGT4 \\
\hline CAWG_00848 & SSH1 & CAWG_02090 & TRK1 & CAWG_01302 & TUB2 & & \\
\hline \multicolumn{8}{|c|}{ Signal transduction mechanism } \\
\hline CAWG_04580 & RIM21 & CAWG_00431 & SWE1 & & & & \\
\hline \multicolumn{8}{|c|}{ Unclassified proteins } \\
\hline CAWG_00151 & orf19.4922 & CAWG_04123 & orf19.862 & CAWG_03695 & orf19.4706 & CAWG_04133 & orf19.850 \\
\hline CAWG_01315 & orf19.6048 & CAWG_05664 & orf19.1344 & CAWG_04023 & orf19.1580 & CAWG_04799 & orf19.3910 \\
\hline \multicolumn{8}{|l|}{ Down-regulated (53) } \\
\hline \multicolumn{8}{|l|}{ Metabolism } \\
\hline CAWG_02002 & URA2 & CAWG_03174 & MNN4 & CAWG_06095 & GPD1 & & \\
\hline \multicolumn{8}{|l|}{ Transcription } \\
\hline CAWG_03683 & MDN1 & CAWG_04089 & STP4 & & & & \\
\hline \multicolumn{8}{|l|}{ Protein synthesis } \\
\hline CAWG_00892 & REI1 & CAWG_05130 & NIP7 & CAWG_05006 & NOG2 & CAWG_05890 & NSAl \\
\hline CAWG_03515 & HCA4 & CAWG_05685 & ENP2 & CAWG_05072 & MRT4 & CAWG_06009 & PES1 \\
\hline CAWG_04963 & $S P B 1$ & CAWG_05748 & UTP18 & CAWG_02769 & MAK21 & & \\
\hline \multicolumn{8}{|c|}{ Cellular transport, transport facilities and transport routes } \\
\hline CAWG_00254 & MUP1 & CAWG_01758 & QDR1 & CAWG_01009 & PDR16 & CAWG_05897 & SIT1 \\
\hline CAWG_03747 & $\mathrm{RCH1}$ & CAWG_01334 & ENA2 & CAWG_05173 & YHM1 & CAWG_00353 & ALP1 \\
\hline CAWG_04346 & CNT & CAWG_01729 & TPO4 & CAWG_05325 & GNP1 & CAWG_00547 & TPO3 \\
\hline \multicolumn{8}{|c|}{ Signal transduction mechanism } \\
\hline CAWG_01171 & SHA3 & CAWG_02761 & RAS2 & & & & \\
\hline \multicolumn{8}{|c|}{ Unclassified proteins } \\
\hline CAWG_00174 & orf19.6355 & CAWG_03036 & orf19.6770 & CAWG_05031 & orf19.5628 & CAWG_05230 & orf19.3449 \\
\hline CAWG_00337 & orf19.2319 & CAWG_03114 & orf19.3089 & CAWG_05139 & orf19.3469 & CAWG_05320 & orf19.1200 \\
\hline CAWG_00416 & orf19.4886 & CAWG_03529 & orf19.2730 & CAWG_05144 & orf19.3463 & CAWG_05329 & orf19.1189 \\
\hline CAWG_00694 & orf19.4445 & CAWG_04078 & orf19.5785 & CAWG_05179 & orf19.3393 & CAWG_05461 & orf19.7011 \\
\hline CAWG_00989 & orf19.4479 & CAWG_04724 & orf19.6660 & CAWG_05189 & orf19.3406 & CAWG_06060 & orf19.1363 \\
\hline CAWG_01012 & orf19.1030 & CAWG_05000 & orf19.5747 & CAWG_05229 & orf19.3448 & & \\
\hline
\end{tabular}

pmr1 and the gdt1/gdt1 pmr1/pmr1 mutants (SuppInfo 2 [GEO Accession number: GSE100737]). In addition, we have observed that expression of CaSWI4 is upregulated due to deletion of CaGDT1 and/or CaPMR1, while expression of $B E M 2$ is down regulated due to the deletion of CaPMR1 (Additional file 1: Table S4). CaSWI4 encodes one of terminal transcription factors of the CWI pathway and its mutants are sensitive to the cell wall-interfering agent caffeine [58]. Bem2 is a negative regulator of the central CWI regulator Rho1 in $S$. cerevisiae, albeit not characterized in C. albicans [46]. These results agree with our observations on the activation of Mkc1- and Cek1-mediated CWI signaling in these mutants (Fig. 4) as well as the previous study [57]. Since $\mathrm{Ca}^{2+}$-induced upregulation of $\mathrm{CHS}$ promoters is independent of the CWI signaling [57], inhibition of expression of both $\mathrm{CaCHS} 2$ and $\mathrm{CaCHS} 3$ by CsA might contribute to defects in the integrity of the external cell wall and intracellular vacuoles of $C$. albicans cells lacking both $C a G D T 1$ and $C a P M R 1$, leading to their death. 


\section{Conclusions}

In this study, we have demonstrated that CaPmr1 is the major player in the regulation of calcium homeostasis and cell wall stress, while CaGdt1 plays a compensatory role for CaPmr1 in the Golgi compartment in C. albicans. It is interesting to note that mammalian TMEM165/Gdt1 is regulated at posttranslational level and directed from the Golgi to lysosomes for degradation in response to high $\mathrm{Mn}^{2+}$ concentrations [48]. In contrast, expression of ScPMR1 is regulated at the transcriptional level, positively mediated by the transcription activator Crz1 through the calcium/calcineurin signaling pathway and negatively mediated by the transcription repressor Nrg1 through the Rim101/Nrg1 pathway [7]. In this way, Pmr1 functions as a major sensor for intracellular $\mathrm{Ca}^{2+}$ and $\mathrm{Mn}^{2+}$ concentrations to elicit a relatively slow and profound response to a change in intracellular calcium homeostasis, while Gdt1 acts as a fast modulator for the ion homeostasis in the Golgi. This combination of temporal (Pmr1) and spatial (Gdt1) regulation of key players in the Golgi might be an efficient way to control the complicated glycosylation process in eukaryotes.

\section{Additional file}

Additional file 1: Figure S1. Functions of SCGDT1 and CaGDT1. Figure

S2. Strategies for chromosomally tagging GFP to the C-terminus of CaGdt1 and tagging HA to the C-terminus of CaPmr1. Figure S3. Co-localization of CaGDT1-GFP and CaPMR1-HA in WJCA111 cells through indirect immunofluorescent approach in response to calcium stress. Figure S4. Semi-quantitation of expression levels of selected 15 genes by RT-PCR. Figure S5 Growth assay of the wild type CAl4, the gdt1/gdt1, the $\mathrm{pmr} 1 / \mathrm{pmr} 1$ and the $g d t 1 / g d t 1$ pmr1/pmr1 mutants. Table S1. Primers used in this study. Table S2. Genes involved in the N-linked glycosylation process. Table S3. Genes involved in the O-linked glycosylation process. Table S4. List of 20 genes involved in the cell wall integrity pathway in Candida albicans. (PDF $2978 \mathrm{~kb}$ )

\section{Abbreviations \\ BSA: bovine serum albumin; CDG: congenital disorders of glycosylation; CFW: calcofluor white; CR: Congo red; CSA: cyclosporine A; CWI: cell wall integrity; ER: endoplasmic reticulum; GFP: green florescent protein; HEPES: hydroxyethyl piperazineethanesulfonic acid; MAPK: mitogen-activated protein kinase; PBS: phosphate buffer saline; PCR: polymerase chain reaction; RPKM: reads per kilobase million; RT: reverse transcription; \\ TMEM165: transmembrane protein 165; UPF0016: uncharacterized protein family UPF0016; YPD: yeast peptone dextron}

\section{Acknowledgements}

We are grateful to Neil A.R. Gow and Christophe Denfert for kindly providing reagents.

\section{Funding}

This work was funded by the National Natural Science Foundation of China to LJ (No. 81571966 and No. 81371784).

\section{Availability of data and materials}

All data generated or analyzed during this study are included in this published article and deposited in the database Gene Expression Omnibus (GEO) site.

\section{Authors' contributions}

$\mathrm{L}$ designed the study and wrote the manuscript. LJ, JW and NS performed the experiments. $L$ and KWC analyzed the data. All authors read and approved the final manuscript.

\section{Ethics approval and consent to participate} N/A

\section{Consent for publication}

All authors approved the final manuscript.

\section{Competing interests}

The authors declare that they have no competing interests.

\section{Publisher's Note}

Springer Nature remains neutral with regard to jurisdictional claims in published maps and institutional affiliations.

\section{Author details}

${ }^{1}$ Laboratory for Yeast Molecular and Cell Biology, School of Agricultural Engineering and Food Science, Shandong University of Technology, Zibo, Shandong, China. ${ }^{2}$ Department of Food Engineering, Weihai Ocean Vocational College, Weihai, Shandong, China. ${ }^{3}$ Department of Biology, the Johns Hopkins University, Baltimore, MD, USA.

Received: 16 February 2018 Accepted: 12 June 2018

Published online: 28 June 2018

References

1. Medler KF. Calcium signaling in taste cells: regulation required. Chem Senses. 2010;35:753-65.

2. Cui J, Kaandorp JA, Sloot PM, Lloyd CM, Filatov MV. Calcium homeostasis and signaling in yeast cells and cardiac myocytes. FEMS Yeast Res. 2009;9: 1137-47.

3. Cunningham KW. Acidic calcium stores of Saccharomyces cerevisiae. Cell Calcium. 2011;50:129-38.

4. Cyert MS. (2003) Calcineurin signaling in Saccharomyces cerevisiae: how yeast go crazy in response to stress. Biochem Biophys Res Commun. 2003; 311:1143-50.

5. Martin DC, Kim H, Mackin NA, Maldonado-Báez L, Evangelista CC Jr, Beaudry VG, Dudgeon DD, Naiman DQ, Erdman SE, Cunningham KW. New regulators of a high affinity $\mathrm{Ca}^{2+}$ influx system revealed through a genomewide screen in yeast. J Biol Chem. 2011;286:10744-54.

6. Demaegd D, Foulquier F, Colinet AS, Gremillon L, Legr D, Mariot P, Peiter E, van Schaftingen E, Matthijs G, Morsomme P. Newly characterized Golgilocalized family of proteins is involved in calcium and $\mathrm{pH}$ homeostasis in yeast and human cells. Proc Natl Acad Sci U S A. 2013;110:6859-64.

7. Zhao Y, Du J, Xiong B, Xu H, Jiang L. ESCRT components regulate the expression of the ER/Golgi calcium pump gene PMR1 through the Rim101/ Nrg1 pathway in budding yeast. J Mol Cell Biol. 2013;5:336-44.

8. Ding X, Yu Q, Xu N, Wang Y, Cheng X, Qian K, Zhao Q, Zhang B, Xing L, Li $M$. Ecm7, a regulator of HACS, functions in calcium homeostasis maintenance, oxidative stress response and hyphal development in Candida albicans. Fungal Genet Biol. 2013;57:23-32.

9. Brand A, Lee K, Veses V, Gow NA. Calcium homeostasis is required for contact-dependent helical and sinusoidal tip growth in Candida albicans hyphae. Mol Microbiol. 2009;71:1155-64.

10. Bates S, MacCallum DM, Bertram G, Munro CA, Hughes HB, Buurman ET, Brown AJ, Odds FC, Gow NA. Candida albicans pmr1p, a secretory pathway P-type $\mathrm{Ca}^{2+} / \mathrm{Mn}^{2+}$-ATPase, is required for glycosylation and virulence. J Biol Chem. 2005:280:23408-15.

11. Sanglard D, Ischer F, Marchetti O, Entenza J, Bille J. Calcineurin a of Candida albicans: involvement in antifungal tolerance, cell morphogenesis and virulence. Mol Microbiol. 2003;48:959-76.

12. Zhao $Y$, Yan H, Happeck R, Peiter-Volk T, Xu H, Zhang Y, Peiter E, van Oostende Triplet C, Whiteway M, Jiang L. The plasma membrane protein Rch1 is a negative regulator of cytosolic calcium homeostasis and positively regulated by the calcium/calcineurin signaling pathway in budding yeast. Eur J Cell Biol. 2016;95:164-74. 
13. Jiang L, Alber J, Wang J, Du W, Li X, Geyer J. The Candida albicans plasma membrane protein Rch1p a member of the vertebrate SLC10 carrier family, is a novel regulator of cytosolic $\mathrm{Ca}^{2+}$ homoeostasis. Biochem J. 2012;444:497-502.

14. Alber J, Jiang L, Geyer J. CaRch1p does not functionally interact with the high-affinity $\mathrm{Ca}^{2+}$ influx system (HACS) of Candida albicans. Yeast. 2013;30: 449-57.

15. Xu D, Cheng J, Cao C, Wang L, Jiang L. Genetic interactions between Rch1 and the high-affinity calcium influx system Cch1/Mid1/Ecm7 in the regulation of calcium homeostasis, drug tolerance, hyphal development and virulence in Candida albicans. FEMS Yeast Res. 2015;15(7). https://doi. org/10.1093/femsyr/fov079.

16. Gow NA, van de Veerdonk FL, Brown AJ, Netea MG. Candida albicans morphogenesis and host defence: discriminating invasion from colonization. Nat. Rev. Microbiol. 2011;10:112-22.

17. Chauhan N, Latge JP, Calderone R. Signalling and oxidant adaptation in Candida albicans and Aspergillus fumigatus. Nat Rev Microbiol. 2006;4:435-44.

18. Monge RA, Román E, Nombela C, Pla J. The MAP kinase signal transduction network in Candida albicans. Microbiology. 2006;152:905-12.

19. Ene IV, Walker LA, Schiavone M, Lee KK, Martin-Yken H, Dague E, Gow NA, Munro CA, Brown AJ. Cell wall remodeling enzymes modulate fungal cell wall elasticity and osmotic stress resistance. MBio. 2015;6:e00986.

20. Herrero-de-Dios C, Alonso-Monge R, Pla J. The lack of upstream elements of the Cek1 and Hog1 mediated pathways leads to a synthetic lethal phenotype upon osmotic stress in Candida albicans. Fungal Genet Biol. 2014;69:31-42.

21. Navarro-García F, Sanchez M, Pla J, Nombela C. Functional characterization of the MKC1 gene of Candida albicans, which encodes a mitogen-activated protein kinase homolog related to cell integrity. Mol Cell Biol. 1995;15: 2197-206.

22. Hall RA, Gow NA. Mannosylation in Candida albicans: role in cell wall function and immune recognition. Mol Microbiol. 2013;90:1147-61.

23. Diez-Orejas R, Molero G, Navarro-García F, Pla J, Nombela C, Sanchez-Perez M. Reduced virulence of Candida albicans MKC1 mutants: a role for a mitogenactivated protein kinase in pathogenesis. Infect Immun. 1997;65:833-7.

24. Csank C, Schröppel K, Leberer E, Harcus D, Mohamed O, Meloche S, Thomas DY, Whiteway M. Roles of the Candida albicans mitogen-activated protein kinase homolog, Cek1p, in hyphal development and systemic candidiasis. Infect Immun. 1998;66:2713-21.

25. Foulquier F, Amyere M, Jaeken J, Zeevaert R, Schollen E, Race V, Bammens R, Morelle W, Rosnoblet C, Legrand D, Demaegd D, Buist N, Cheillan D, Guffon N, Morsomme P, Annaert W, Freeze HH, Van Schaftingen E, Vikkula M, Matthijs G. TMEM165 deficiency causes a congenital disorder of glycosylation. Am J Hum Genet. 2012;91:15-26.

26. Colinet AS, Thines L, Deschamps A, Flémal G, Demaegd D, Morsomme P. Acidic and uncharged polar residues in the consensus motifs of the yeast $\mathrm{Ca} 2+$ transporter Gdt1p are required for calcium transport. Cell Microbiol. 2017;19(7) https://doi.org/10.1111/cmi.12729.

27. Colinet AS, Sengottaiyan P, Deschamps A, Colsoul ML, Thines L, Demaegd $D$, Duchêne MC, Foulquier F, Hols $P$, Morsomme P. Yeast Gdt1 is a Golgilocalized calcium transporter required for stress-induced calcium signaling and protein glycosylation. Sci Rep. 2016;6:24282.

28. Reuss O, Vik A, Kolter R, Morschhäuser J. The SAT1 flipper, an optimized tool for gene disruption in Candida albicans. Gene. 2004;341:119-27.

29. Li X, Huang X, Zhao J, Zhao J, Wei Y, Jiang L. The MAP kinase-activated protein kinase Rck2p plays a role in rapamycin sensitivity in Saccharomyces cerevisiae and Candida albicans. FEMS Yeast Res. 2008:8:715-24.

30. Wang Y, Wang J, Cheng J, Xu D, Jiang L. Genetic interactions between the Golgi $\mathrm{Ca}^{2+} / \mathrm{H}^{+}$exchanger Gdt1 and the plasma membrane calcium channel Cch1/Mid1 in the regulation of calcium homeostasis, stress response and virulence in Candida albicans. FEMS Yeast Res. 2015;15(7). https://doi.org/10. 1093/femsyr/fov069

31. Jiang L, Niu S, Clines KL, Burke DJ, Sturgill TW. Analyses of the effects of Rck2p mutants on Pbs2pDD-induced toxicity in Saccharomyces cervisiae identify a MAP kinase docking motif, and unexpected functional inactivation due to acidic substitution of T379. Mol Genet Genomics. 2004 271:208-19.

32. Stefan $\mathrm{CP}$, Cunningham KW. Kch1 family proteins mediate essential responses to endoplasmic reticulum stresses in the Yeasts Saccharomyces cerevisiae and Candida albicans. J B Chem. 2013;288:34861-70.

33. Zhao J, Sun X, Fang J, Liu W, Feng C, Jiang L. Identification and characterization of the type $2 \mathrm{C}$ protein phosphatase Ptc $4 \mathrm{p}$ in the human fungal pathogen Candida albicans. Yeast. 2010;27:149-57.
34. Lavoie H, Sellam A, Askew C, Nantel A, Whiteway M. A toolbox for epitopetagging and genome-wide location analysis in Candida albicans. BMC Genomics. 2008;9:578.

35. Feng J, Duan $Y$, Qin $Y$, Sun W, Zhuang Z, Zhu D, Jiang L. The N-terminal pY33XL motif of CaPsy2 is critical for the function of protein phosphatase 4 in CaRad53 deactivation, DNA damage-induced filamentation and virulence in Candida albicans. Intl J Med Microbiol. 2017;307:471-80.

36. Mortazavi A, Williams BA, McCue K, Schaeffer L, Wold B. Mapping and quantifying mammalian transcriptomes by RNA-Seq. Nat Methods. 2008;5:621-8.

37. Romualdi C, Bortoluzzi S, D'Alessi F, Danieli GA. IDEG6: a web tool for detection of differentially expressed genes in multiple tag sampling experiments. Physiol Genomics. 2003;12:159-62.

38. Rosnoblet $C$, Legrand D, Demaegd D, Hacine-Gherbi $H$, de Bettignies $G$, Bammens R, Borrego C, Duvet S, Morsomme P, Matthijs G, Foulquier F. Impact of disease-causing mutations on TMEM165 subcellular localization, a recently identified protein involved in CDG-II. Hum Mol Genet. 2013;22:2914-28.

39. Madeo $F$, Fröhlich $E$, Fröhlich KU. A yeast mutant showing diagnostic markers of early and late apoptosis. J Cell Biol. 1997;139:729-34.

40. Buttner S, Eisenberg T, Carmona-Gutierrez D, Ruli D, Knauer H, Ruckenstuhl C, Sigrist C, Wissing S, Kollroser M, Fröhlich KU, Sigrist S, Madeo F. Endonuclease G regulates budding yeast life and death. Mol Cell. 2007;25: 233-46.

41. Halachmi D, Eilam Y. Elevated cytosolic free $\mathrm{Ca}^{2+}$ concentrations and massive $\mathrm{Ca}^{2+}$ accumulation within vacuoles, in yeast mutant lacking PMR1, a homolog of $\mathrm{Ca}^{2+}$-ATPase. FEBS Lett. 1996;392:194-200.

42. Strayle J, Pozzan T, Rudolph HK. Steady-state free $\mathrm{Ca}^{2+}$ in the yeast endoplasmic reticulum reaches only 10 microM and is mainly controlled by the secretory pathway pump Pmr1. EMBO J. 1999;18:4733-43.

43. Pardini G, de Groot PW, Coste AT, Karababa M, Klis FM, de Koster CG, Sanglard D. The CRH family coding for cell wall lycosylphosphatidylinositol proteins with a predicted transglycosidase domain affects cell wall organization and virulence of Candida albicans. J Biol Chem. 2006;281: 40399-411.

44. Dias PJ, Sá-Correia I. The drug: $\mathrm{H}^{+}$antiporters of family 2 (DHA2), siderophore transporters (ARN) and glutathione: $\mathrm{H}^{+}$antiporters (GEX) have a common evolutionary origin in hemiascomycete yeasts. BMC Genomics. 2013;14:901.

45. Loewen SK, Ng AM, Mohabir NN, Baldwin SA, Cass CE, Young JD. Functional characterization of a $\mathrm{H}^{+}$/nucleoside co-transporter (CaCNT) from Candida albicans, a fungal member of the concentrative nucleoside transporter (CNT) family of membrane proteins. Yeast. 2003;20:661-75.

46. Xiong B, Zhang L, Xu H, Yang Y, Jiang L. Cadmium induces the activation of cell wall integrity pathway in budding yeast. Chem Biol Interact. 2015;240:316-23.

47. Potelle S, Dulary E, Climer L, Duvet S, Morelle W, Vicogne D, Lebredonchel E, Houdou M, Spriet C, Krzewinski-Recchi MA, Peanne R, Klein A, de Bettignies G, Morsomme P, Matthijs G, Marquardt T, Lupashin V, Foulquier F. Manganese-induced turnover of TMEM165. Biochem J. 2017:474:1481-93.

48. Dulary E, Potelle S, Legrand D, Foulquier F. TMEM165 deficiencies in Congenital Disorders of Glycosylation type II (CDG-II): Clues and evidences for roles of the protein in Golgi functions and ion homeostasis. Tissue Cell. 2017:49:150-6.

49. Shah $\mathrm{SZ}$, Hussain $\mathrm{T}$, Zhao $\mathrm{D}$, Yang L. A central role for calcineurin in protein misfolding neurodegenerative diseases. Cell Mol Life Sci. 2017;74:1061-74.

50. Kim H, Kim A, Cunningham KW. Vacuolar H+-ATPase (V-ATPase) promotes vacuolar membrane permeabilization and nonapoptotic death in stressed yeast. J Biol Chem. 2012;287:19029-39.

51. Jiang L, Xu D, Hameed A, Fang T, Bakr Ahmad Fazili A, Asghar F. The plasma membrane protein Rch1 and the Golgi/ER calcium pump Pmr1 have an additive effect on filamentation in Candida albicans. Fungal Genet Biol. 2018;115:1-8.

52. Burda P, Aebi M. The dolichol pathway of N-linked glycosylation. Biochim Biophys Acta. 1999;1426:239-57.

53. Welti M. Regulation of dolichol-linked glycosylation. Glycoconj J. 2013: 30:51-6.

54. Chavan M, Suzuki T, Rekowicz M, Lennarz W. Genetic, biochemical, and morphological evidence for the involvement of $\mathrm{N}$-glycosylation in biosynthesis of the cell wall beta1,6-glucan of Saccharomyces cerevisiae. Proc Natl Acad Sci U S A. 2003;100:15381-6.

55. Halim A, Larsen IS, Neubert P, Joshi HJ, Petersen BL, Vakhrushev SY, Strahl S, Clausen $\mathrm{H}$. Discovery of a nucleocytoplasmic O-mannose glycoproteome in yeast. Proc Natl Acad Sci U S A. 2015;112:15648-53. 
56. Arroyo J, Hutzler J, Bermejo C, Ragni E, García-Cantalejo J, Botías P, Piberger $H$, Schott A, Sanz AB, Strahl S. Functional and genomic analyses of blocked protein O-mannosylation in baker's yeast. Mol Microbiol. 2011 Mar;79(6): 1529-46.

57. Munro CA, Selvaggini S, de Bruijn I, Walker L, Lenardon MD, Gerssen B, Milne S, Brown AJ, Gow NA. The PKC, HOG and $\mathrm{Ca}^{2+}$ signalling pathways coordinately regulate chitin synthesis in Candida albicans. Mol Microbiol. 2007:63:1399-413.

58. LaFayette SL, Collins C, Zaas AK, Schell WA, Betancourt-Quiroz M, Gunatilaka $A A$, Perfect JR, Cowen LE. PKC signaling regulates drug resistance of the fungal pathogen Candida albicans via circuitry comprised of $\mathrm{Mkcl}$, calcineurin, and Hsp90. PLoS Pathog. 2010;6:e1001069.

Ready to submit your research? Choose BMC and benefit from:

- fast, convenient online submission

- thorough peer review by experienced researchers in your field

- rapid publication on acceptance

- support for research data, including large and complex data types

- gold Open Access which fosters wider collaboration and increased citations

- maximum visibility for your research: over $100 \mathrm{M}$ website views per year 